\title{
Events for adolescent smoking cessation : the development, implementation and evaluation of a Danish adolescent smoking cessation intervention.
}

Citation for published version (APA):

Dalum, P. (2009). Events for adolescent smoking cessation : the development, implementation and evaluation of a Danish adolescent smoking cessation intervention. [Doctoral Thesis, Maastricht University]. Copenhagen. https://doi.org/10.26481/dis.20090910pd

Document status and date:

Published: 01/01/2009

DOI:

10.26481/dis.20090910pd

Document Version:

Publisher's PDF, also known as Version of record

Please check the document version of this publication:

- A submitted manuscript is the version of the article upon submission and before peer-review. There can be important differences between the submitted version and the official published version of record. People interested in the research are advised to contact the author for the final version of the publication, or visit the DOI to the publisher's website.

- The final author version and the galley proof are versions of the publication after peer review.

- The final published version features the final layout of the paper including the volume, issue and page numbers.

Link to publication

\footnotetext{
General rights rights.

- You may freely distribute the URL identifying the publication in the public portal. please follow below link for the End User Agreement:

www.umlib.nl/taverne-license

Take down policy

If you believe that this document breaches copyright please contact us at:

repository@maastrichtuniversity.nl

providing details and we will investigate your claim.
}

Copyright and moral rights for the publications made accessible in the public portal are retained by the authors and/or other copyright owners and it is a condition of accessing publications that users recognise and abide by the legal requirements associated with these

- Users may download and print one copy of any publication from the public portal for the purpose of private study or research.

- You may not further distribute the material or use it for any profit-making activity or commercial gain

If the publication is distributed under the terms of Article $25 \mathrm{fa}$ of the Dutch Copyright Act, indicated by the "Taverne" license above, 


\section{Events for Adolescent Smoking Cessation}

The Development, Implementation and Evaluation of

a Danish Adolescent Smoking Cessation Intervention

\section{DISSERTATION}

\section{To obtain the degree of doctor at Maastricht University,}

on the authority of the Rector Magnificus Prof.dr: G.P.M.F. Mols, in accordance with the decision of the Board of the Deans,

to be defended in public on

Thursday September 10, 2009 at 12.00 hours

by

Peter Dalum 
Events for Adolescent Smoking Cessation

\section{Promotores:}

Prof.dr. H.P. Schaalma

ProE.dr. G.J. Kok

\section{Review committee:}

Prof.dr. B. van den Borne (Chair)

Prof.di: L. Aaro (University of Bergen, Norway)

Dr. S. Kremers

Prof.dr. G.S. Parcel (University of Texas, USA)

Dr. R.A.C. Ruiter

Events for Adolescent Smoking Cessation - The Development, Implementation and Evaluation of a Danish Adolescent Smoking Cessation Intervention

Peter Dalum

Graphic layout: Helle Træholt Wang

Danish Cancer Society 2009

Dept. of Cancer Prevention and Documentation

Strandboulevarden 49

DIK-2100 Copenhagen

Phone 35257500

www.rygning.cotn

www.liv.dk

www:xhale.dk

www.cancer.dk

Cover and printing: Erhvervsskolernes Forlag

ISBN: 978-87-7082-069-1

The Thesis can be purchased at the Danish Cancer Society.

Copyright 2009 C Danish Cancer Society. All rights reserved. 


\section{Content}

Introduction

Qualitative study

21

Intervention development

41

Evaluation

61

Discussion

81

Summary

91

Reference List

95 
Events for Adolescent Smoking Cessation 


\section{Preface}

"I dorit plan to bave a long life" Adolescent male in a Danish youth magazine 2008

Although the dangers of smoking have been known for more than half a century little has been done to help adolescents and young adults quitting smoking. Only in recent years focus have been on this target group, and to date there is no firm consensus about the best approach. 'This thesis describes the systematic development and evaluation of a school based adolescent smoking cessation intervention targeting smoking youth aged 15-21. 
Events for Adolescent Smoking Cessation
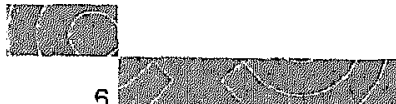


\section{Acknowledgements}

Writing this $\mathrm{PhD}$ would have been a never ending process if it was not for the help from others. My colleagues in the project Adolescents \& Smoking at the Danish Cancer Society, in particular Poul Dengsøe Jensen and Per Kim Nielsen, have given invaluable professional and personal support in the process. Learning how to handle data and to analyze them has been one of the major challenges for me. If it was not for help from Niels Christensen questionnaires would still be in boxes, and without the help from Georg Paludan-Müller I would still be fumbling around with SAS programming. Gerda Engholm and Georg taught me how to eat an elephant (statt in one end and take one bite at a time) which was how I managed to get through the data analyzing process. Having Herman Schaalma and Gerjo Kok as supervisors has been a privilege few are granted. Not only did they provide scientific expertise but also theit positive and supportive attitude has been impressive. Arne Randrup taught me how to cope with stress and helped me find resources to get through the last year of the process. Finally, my family $\Lambda$ nette, Luka, Sakse, Nora and Sejer constantly have given me support and reminded me about what really matters in life... 
Introduction 
Events for Adolescent Smoking Cessation

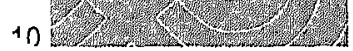


Introduction

In Denmark smoking causes approximately 14,000 deaths annually (1) with the life expectancy of smokers being reduced by 10 years on average (2). In the Danish National Plan on Cancer (2000) it is stated that if a nationwide smoking stop took immediate effect, $26 \%$ of all cases of cancer among males and $14 \%$ of all cases among females in Denmark could be avoided. The effect would be noticeable after $7-10$ years but the full implications would not be realised until decades later. Complete smoking cessation would increase the average lifespan in Denmark by 2.8 years (3).

Smoking has been telated to a range of conditions that alrcady affect the quality of life in the younger age groups (2). Smoking teduces an individual's physical conditioning (4); it retards the healing process of wounds and incteases the tisk of wound infections (5). Smokers develop mote wrinkles than non-smokers (6) and among females it has been found that smoking increases the tisk of developing psoriasis (7). Smoking affects the senses: both the olfactory sense and the sense of taste ate reduced among smokers (8), and a range of eyc diseases has been related to smoking (9). Smokers have an increased risk of periodontal disease (10). Smokers also have an increased tisk of both vital and bacterial infections (2). Fertility is reduced among smokers (11), and a range of problems in pregnancy has been related to smoking (2). In addition, adolescent smokers have a lower self-estimation of own health $(12 ; 13)$, and with respect to lung cancer it has been shown that the teenage body is more receptive to the harmful effects of smoking (14;15).

In 2001-2002 the Danish Cancer Society conducted a pilot study to test a 'conventional' group-based smoking cessation intervention in three different school settings for students aged 16-20 in Denmark (16). The study showed that most schools did not consider smoking cessation a relevant topic for the school curtriculum and concluded that the prerequisites for smoking-cessation courses were not present at the schools at that time. In addition, it was found that despite the cessation groups being held in school hours, only about 5\% of the student smokers were recruited. These findings are in line with findings from McDonald (1999), who found that the median recruitment rate for adult smoking cessation. interventions was $2.0 \%$ (17), and a study of Backinger et al., who reported that a researcher might expect between 2 and $10 \%$ recruitment to adolescent smoking: cessation interventions (18). Further, several studies have indicated that adolescents have somewhat negative petceptions of formal cessation support. $\Lambda$ dolescents consider interventions as patronizing and something for older, addicted 
smokers (19;20); they consider 'willpower' as the most important determinant of smoking cessation (21); and they prefer self-help programmes, friends' support or no help at all rather than joining a formal cessation attempt (22).

Therefore, the challenge in future cessation interventions is not only to develop programmes based on effective methods, but also during the development process to consider the barriers to recruiting adolescent smokers, and to design intersentions to recruit a sizeable number of the adolescent smokers.

In the following sections, the scientific literature about determinants of adolescent smoking cessation is reviewed and an overview is given of the existing interventions and experiences at the time of the intervention development ptocess in 2004. Lastly, there is a description of the planning tool, Intervention Mapping, used for developing the intervention.

\section{Smoking prevalence and quitting intentions among Danish youth}

A national cross-sectional survey conducted among $16-20$ year olds in Denmark in 2001 found $24 \%$ were daily smokers and $8 \%$ were occasional smokers among males and $23 \%$ were daily smokers and $13 \%$ were occasional smokers among females (23). Among the smokers, $36 \%$ of the males and $35 \%$ of the females would like to quit smoking, 39\% of all smokers had attempted to quit and $47 \%$ had attempted to reduce cigarette consumption within the last year; $17 \%$ planned to quit smoking with the next six months and $6 \%$ planned to quit within the next month. Among all the young people surveyed (both smokers and non-smokers), $2.6 \%$ said they had quit smoking duting the last year. This indicate that approximately $8 \%$ of the former smokers had quitted within the last year.

Prospective studies confirm that smoking cessation is a 'natural' process among adolescents. For instance, Paavola et al. $(1996 ; 2001)$ found that $26 \%$ of daily smokers at age 15 years quit before the age of 28 years. In the period $15-21$ years, $21 \%$ quit $(24 ; 25)$. Stanton et al. (1996) found that while $11 \%$ of the experimental smokers quit during the period 15-18 years, only $3 \%$ of the daily smokers quit during the same period (26). Sussman et al. (1998) compared the rates of spontaneous smoking cessation of various studies on the subject and found that the number of young people who quit smoking varied from $5 \%$ to approximately $44 \%$ (27). This difference stemmed, among other things, from the different definitions of a smoker used in the studies reviewed.

\section{Factors influencing smoking cessation}

Several studies have been conducted to determine which factors affect smoking cessation among the young. Roughly, these can be subdivided into structural fac-
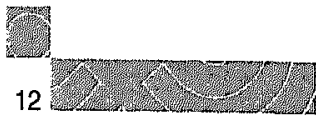
tors, social infuences, physical determinants, determinants related to psychological and social wellbeing, and cognitive determinants.

\section{Structural factors}

Although it is genetally assumed that a price increase reduces cigarette consunption (28), the effects of pricing with specific regard to smoking cessation among adolescents have been little studied. Biener et al. (1998) surveyed the consequences of increases in tobacco prices among young people and found that $21 \%$ had considered quitting and that $26 \%$ had either reduced their consumption or had changed to cheaper cigarette brands after the price increase (29).

Reducing access to cigarettes is another area where the evidence with regard to adolescent smoking cessation is weak. Forster et al. (1998) surveyed the effect of reducing the access of young people to tobacco (30). They examined the development of the number of daily smokers, occasional smokers and experimental smokers, respectively, over three years. The intervention consisted of introducing checks and fines in order to ensure that the law against sale of tobacco products to persons under 18 years of age was being upheld as well as reducing the young people's access to tobacco vending machines. $A$ fter three yeat's, relatively fewer daily smokers were found among the intervention groups than among the control groups. However, the difference was not significant and it was not demonstrated if the difference was due to fewer youth taking up smoking or to more youth quitting.

\section{Social influences}

A range of studies have found that smokers who associate with other smokets ate less likely to quit smoking at a later date (25;31-39). Tucker et al. (201/2) found this among females (39), and Hansen et al. (1985) found the number of fitends who smoked related to cessation attempts but not to cessation success tates (37). Skinner et al. (1985) found that there was a negative correlation between having a smoker as a close friend and the adolescent's likclihood of cyuitting smoking (40).

Pallonen et al. (1998) found that former smokers feel especially tempted to smoke when offered to do so by members of their social circle (41), and 'Tueker et al. (2002) found that the more successful quittets among males were subjected to fewer cigarette offers (39). Ellickson et al. (2001a) found that more people quit smoking if they experienced support from friends, while Chassin et al. (1984) found that quitting can lead to changes in the social circle in the direction of fewer smoking friends/acquaintances $(33 ; 35)$. 
Several studies have found that smoking among parents is negatively related to cessation in adolescents. Chassin et al. (1984) and Paavola et al. (2001) found that smoking among both parents was negatively associated with smoking cessation $(25 ; 42)$, whereas Zhu et al. (1998) found an negative association only between mothers' smoking and cessation (43). Hansen et al. found that parents' smoking was negatively related to whether the adolescent attempted to quit smoking, but not to whether the attempt was successful (37). Chassin et al. (2002) found that a parent's quitting was only positively related to quitting if both parents had quit or if the other parent was a non-smoker (44). Farkas et al. found that cessation among parents was positively relateted to adolescent cessation, but that it had more effect the earlier it occurred (45).

Some studies have found that parents' attitudes towards smoking are related to whether their youngsters will continue smoking. Chassin et al. (1984) found this connection among younger teenagers (33), whereas Eillickson et al. (2001b) and Tucker et al. (2002) found that parents' attitudes towards smoking was relevant only among females (36;39). O'Byrne et al. (2002) found that parental attitudes towards upbringing were significant in relation to whether their youngsters choose to quit smoking (46). They found that young people who experienced a good balance between intimacies (contact between parents and child) and autonomy (that the child is allowed to make up its own mind) had a greater chance of successfully quitting. In line with this, Skinner et al, (1985) found that quitters had a closer connection to their father than those who continued smoking (4.()).

\section{Physical determinants}

Siqueita et al. (2001) found that among the young who had tried to quit and had failed more had experienced nicotine craving than among those who had succeeded in quitting (47). Additionally, Prokhorov et al. (1996) found that those who scored highest on nicotine addiction had the lowest ability and motivation to quit among the young (48).

The amount of smoking has also been connected to quitting. Pavola et al. (2001), Sargent et al. (1998) and Zhu et al. (1999) al found that occasional smoking is connected to greater likelihood of later quitting than regular smoking $(25 ; 43 ; 49)$, while Schmid (2001), Siqueira et al. (2001) and Sussman et al. (1998) found that high tobacco consumption was related to continued smoking (27;47;50). Tucker et al. (2002) found a significant connection between high consumption and continued use only among females, though the same tendency was found among males (39). Engels et al. (1998) found that a low consumption was a determinant of the degree of motivation to quit between two of the phases in Prochaska and DiClamente's 'Stages of Change': contemplation compared with preparation as well as preparation compared with action (51).

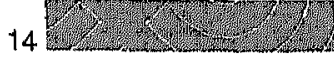


Ellickson et al. (2001a) found that early age was negatively related to quitting (an eatly start means a high likelihood of continued smoking) (35). The same tendency was noticeable among males for Tucker et al. (2002)(39). Engels et al. (1998) found that early debut age was negatively related to the motivation to quit smoking (51).

\section{Factors connected to psychological and social wellbeing}

Lewinsohn et al. (2000) found that youths who have fewer problems with their parents and fewer problems in their daily lives are more likely to quit smoking (38). Bonard et al. (2001) found that continuing smokers had shoplifted to a larger extent than quitters (52). Paavola et al. (2001) found that cessation is cotrelated with a decrease in alcohol consumption (25). Lewinsohn et al. (200)()) found that continuing smoking was associated with drug abuse, and Ellickson et al. (2001) found that there were more continuing smokers who smoked hashish among females (36;38). Paavola et al. (2001) and Rose et al. (1996) found that there are more quitters among young people who have a job $(25 ; 53)$. $\wedge$ number of studies have found that young people doing well at school are more likely to quit smoking $(25 ; 35 ; 38 ; 39 ; 42 ; 53 ; 54)$. Bonard et al. (2001) and Paavola et al. (2001) found that young people who quit smoking are more engaged in activities in their spare time (25;52). Bonard et al. (2001) found that smokers have more friends than do quitters (52). Chassin et al. (1996), Panvola et al. (1996) and Rose et al. (2001) found that quitters adopt mote 'adult-toles' $(25 ; 42 ; 53)$. Zhu et al. (1999) found that continuing smokers demonstrate more symptoms of depression than do quitters (43). Ellickson et al. (2001b) found that among females more quitters came from unbroken families, while Tucker et al. (20012) found this same correlation among males (36;39). Futther, Eillickson et al. (2001b) found that uninterrupted schooling was positively related to quitting (36).

Several surveys have been used to determine if there is a difference between continuing young smokers and quitters in how they handle emotions and the impact of smoking on dealing with emotions. Schmid (2001) found that there were fewer quitters among those who smoke to relax or among those who smoke to cope with negative emotions (50). Both Sussman et al. (1998) and Siqueita et: al. (2001) found that stress is a determinant of continuing smoking (27;47). Siqueirn et al. (2001) further found that the group of continuing smokers to a lesser degree than quitters used cognitive coping methods (such as accepting the state of things, distancing themselves from the problem or looking on the positive side of things) and instead used more 'action' orientated coping strategies.

\section{Cognitive determinants}

Engels et al. (1998) found that low self-efficacy for quitting among smokers in an initial survey at the age of 14-15 years was a determinant of low motivation 
to quit when the youths had reached the age of 17-18 years (51). Ellickson et al. (2001b) found that there was a greater probability that 18 -year-olds who had a strong belief that they could tesist an external pressure to smoke had quit after three years (36). Tucker et al. (2002) found a similar result for females at the agc of 17 years who were surveyed again five years later (39).

Sussman et al. (1998), Tucker et al. (2001a) and Zhu et al. (1999) all found that intentions to either continue smoking or to quit were determinants of later smoking status $(27 ; 39 ; 43)$. Ellickson et al. (2001b) found this correlation among females (36), while Sargent et al. (1998) found that intentions were a determinant only for later smoking habits among occasional smokers (49).

Several findings indicate that young people's attitude toward health affects cessation tates.

Rose et al. (1996) found that quitters were more likely to value a healthy lifestyle than were non-quitters (53), and Ellickson et al. (2001b) found that female quitters perceived themselves to be healthier than a similar group of continuing smokers (36). Romer et al. (2001) found that young people in general underestimate both the general health risks of smoking and their susceptibility to these tisks (55). In addition, they found that those persons who had the highest estimates of both the genetal and personal risk were the most motivated to quit. Rose et al. (1996) found that those young people with a high cigarette consumption who perceived smoking to be dangerous were the most motivated to quit, but, notably, they also found the opposite association among youths with a low consumption (53). In similar vein, Milam et al. (2000) found that young smokers who regarded themselves to be impervious to the damaging effects of cigarette smoke in general smoked less, and they concluded that the feeling of imperviousness among young people is connected to the fact of being less subjected to cigarette smoke (56).

Skinner et al. (1985) and Engels et al. (1998) found a negative association between young people's attitudes towards smoking and smoking cessation (40;51), while Rose et al. (1996) in concurrence with this found that youth with negative attitudes to a larger extent quit smoking (53). Hansen et al. (1995) found that the degree of positive attitudes towards quitting smoking is a determinant for attempting to quit, while the youth with more negative attitudes towards smoking have the greatest probability of succeeding in their attempts to quit (37).

To summarise, successful adolescent quitters experience support for their quitting from friends (40), have parents with negative attitudes to smoking $(37 ; 40 ; 43)$, receive the fewest offers to smoke (43), have parents who have either quit smoking or have never smoked $(5 ; 28 ; 45-47)$, have fewer friends who smoke $(5 ; 35-43)$, smoke the least $(25 ; 27 ; 43 ; 47 ; 49 ; 50)$, started smoking late $(35 ; 39 ; 51)$, are less addicted to nicotine $(47 ; 57)$, come from unbroken families $(36 ; 39)$, have had unin- 
terrupted schooling (36), do not smoke in order to cope with negative emotions or stress $(27 ; 47 ; 50)$, drink less alcohol (25), to a lesser degree use other drugs (36;38), have the fewest psychological and social problems $(36 ; 38 ; 52)$, do well in school $(25 ; 35 ; 38 ; 39 ; 42 ; 53 ; 54)$, have a strong belief that they can quit $(36 ; 39 ; 51)$, feel that the consequences of smoking ate personally relevant $(53 ; 55)$, have intentions to quit smoking in the future $(27 ; 36 ; 39 ; 43)$, and have negative attitudes toward smoking or positive attitudes toward quitting $(37 ; 37 ; 40 ; 51 ; 53)$.

\section{Evidence from existing interventions}

At the time of the development of our smoking programme, it was unclear what conclusions could be drawn from the existing adolescent smoking cessation interventions. We conducted a PubMed search on the search words "adolescence" and "smoking cessation" in 2002 and found 15 studies of various smoking cessation concepts targeting young people.

Five of the studies were on conventional group counselling in schools (58-62). Overall, all studies reported effects on either smoking cessation or consumption. However, the longest follow-up period was 5 months and the method for measuring the effect varied tremendously between studies.

Two of the studies were on interventions in which young people were offered nicotine substitution $(63 ; 64)$. Both studies showed that the interventions had no discernible effect compared with the natural cessation rates among young people of similar age.

One of the studies was on the effect of a mass media campaign on smoking and smoking cessation (65). This study showed a significant reduction of female smokers compared with girls in a control group. The follow-up period of this study was 3 years.

One of the studies was on a web-based smoking cessation programme (66). This study showed significant effects on cessation rates, reduction in consumption and intentions to quit after one month.

Two of the studies were on computer-based smoking cessation (67). One study showed a short-term effect on cessation tates, and the other a short-term effect on intentions to quit. Neither study showed any effect after six months.

Two of the studies wete on the effect of minimal interventions mediated by counsellots in a hospital setting and by dentists, respectively (68;69). One study was a comparative study without a control group between two brief intervention formats which demonstrated that the brief intervention in itself was effective after one month but that there was no discernible difference between the two intervention formats. The other study demonstrated that a brief informational intervention mediated by dentists had no discernible effect after: two yeats.

One of the 15 studies involved a combination of self-help intervention mediated through instructors (70). This study showed a significant effect on consumption rates and attempts to quit after one month. 
Overall, we concluded that although some school-based intervention approaches had shown promising results and although there were some indications of effective programme elements, it was not possible to draw firm conclusions on either intervention settings or effects.

This conclusion was confirmed by a review of McDonald and colleagues (71). On the basis of a review of 20 studies that had been evaluated in a rigorous study design, they concluded that: "Cognitive-bebavioural interventions are a promising approach for belping young smokers quit smoking. Evidence is insufficient to drany other conclusions at this time".

The basic elements of cognitive-behavioural interventions were defined in an additional publication by the same research group (72). 1) Establish self-awareness of tobacco use: tecord tobacco use behaviours; discuss thoughts, beliefs and reasons for using and not using tobacco; and teach about the physical and psychological effects of tobacco use. 2) Let smokers prepare to quit: set a specific and reasonable quit date, choose a quitting strategy, set short-term and long-term goals that match the quitting strategy, and teach about the physical and psychological symptoms of withdirawal. 3) Provide strategies to maintain abstinence: use problem-solving techniques to minimize effects of situational triggers, develop coping skills (thoughts and actions), promote seeking social support from family and peers, and teach strategies to monitor and reinforce progress.

In addition, one comparative intervention study provided interesting insights into the adolescent smoking cessation process. Quinlan and McCaul compared a 'matched' and a 'mismatched' intervention targeting young pre-contemplators (70). 'The 'matched' intervention was based on Prochaska and DiClemente's recommendation that cessation interventions should match smokers 'stage of change'. Quinlan and McCaul took into consideration that their target group was not motivated to quit and designed an intervention that did not include specific quitting advice but that focused on 'why does one smoke', 'economic costs of smoking', 'the consequences of smoking', 'reasons to continue or to quit smoking', 'attaining a more "balanced" view on smoking' and myths and facts about smoking.' 'The mismatched intervention did not consider the participants' cessation stage and therefore included 'action-oriented' topics such as 'cessation methods', 'identification of difficult situations', 'management of difficult situations', 'fix a date for quitting', 'prepare quitting' and 'use of friends for support'. Contrary to expectations, Quinlan and McCaul found that the 'mismatched' intervention was significantly the most efficacious. They concluded that interventions targeted at young people need to be 'action-oriented', even if the target audience are not yet motivated to quit smoking.

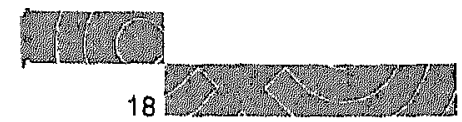




\section{Intervention Mapping}

Intervention Mapping (IN) is a systematic planning tool for developing and implementing theory and evidence-based health promotion interventions (73). IM provides a methodology that ensures that knowledge from practitioners, the target group and the scientific evidence is incorporated in the development process. IM comprises six steps, each with a clear end product (see overview figure in chapter 3). Interventionists are invited to work through the steps iteratively, incorporating insights from later steps in earlier steps. In IM Step 1, a needs assessment is conducted. The planner assesses the health problem, its related behavioural and environmental conditions and associated determinants for the target population. In IM Step 2, important and changeable determinants of the behaviour change are selected and specific change objectives for the intervention programme are specified. In IM Step 3, a list of theoretical change methods is generated that matches the change objectives of Step 2. Subsequently, these methods ate translated into practical intervention strategies. In IM Step 4, the intervention is designed, produced and subjected to a pie-test. This requires organising the strategies into a deliverable programme considering the needs of the target group and the intervention settings. In IM Step 5, a implementation plan is developed. Adoption and implementation of an intervention requires tailoring the programme to the end users and persons responsible for adoption and implementation. In IM Step 6 , an evaluation plan for both implementation and the programmes' efficiency is conducted. IM emphasizes that all steps in the intervention development are evaluated with tegard to both process and effect measures.

One of the key features of IM is that the mapping process leads to high transparency of the decisions taken in the intervention development process. Detailed monitoring demystifies the logic between programme objectives, intervention strategies and their theoretical underpinnings. This transparency is crucial to gain insight into why some interventions ate effective and others are not and when transferring experiences from one intervention context to another (74;75). In addition, IM puts a strong emphasis on incorporating the anticipation of implementation and tecruitment from the start of the planning process.

In the following chapters we present our attempt to develop an effective adolescent smoking cessation intervention with a focus on high recruitment, high implementation and short- and long-term programme effects. In chapter 2 we present a qualitative study of the adolescent smoking cessation process. The purpose of the study was to achieve a better understanding of the adolescent cessation process and the recruitment barriers to intervention participation. In chapter 3 we describe the intervention development and how we used IMI to systematize the evidence and experiences from various sources in the intervention development process. In chapter 4 we present the results of our process- and effect evaluation of the intervention. In chapter 5 we discuss the knowledge 
Events for Adolescent Smoking Cessation

and insights we gained in the process from both our own findings and findings from the more recent literature, which were published after we had planned our intervention. 
2 Qualitative study 
Events for Adolescent Smoking Cessation

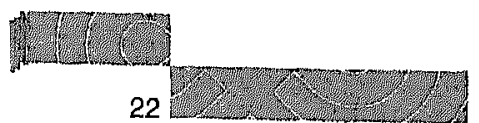




\title{
"I did it my way" - an explorative study of the smoking cessation process among banish youth
}

\author{
Peter Dalum*, Herman Schaalma**, Gert A. Nielsen* \& Gerjo Kok*** \\ Published in: Patient Education and Counseling 73 (2008) 318-324 \\ *Department of Prevention and Documentation, Danish Cancer Society, Den- \\ mark \\ **Department of Experimental Psychology, Faculty of Psychology, Maastricht \\ University, The Netherlands
}

Running head: The youth smoking cessation process

Correspondence should be addressed to:

Peter Dalum, Department of Prevention and Documentation, Danish Cancer Society, Strandbldv. 49, DK-2100, Copenhagen, Denmark, email: pd@cancer.dk 


\section{Abstract}

Objective: To explore the smoking cessation process of adolescents and their attitudes and beliefs towatds smoking cessation and cessation interventions.

Metbod: Focus group discussions and individual interviews during April-May 2004 with 26 persons aged 15-21yrs who all initiated a quit attempt on 1 January 2004.

Results: The approach towards all stages of the youth smoking cessation process varied greatly among both successful and unsuccessful quitters. Apart from 'commitment' or the amount of energy put into a cessation attempt, there were no differences in the way successful and unsuccessful quitters approached the quit attempt. 'Smoking friends' and 'social support' were important for maintaining cessation. Further, participants had negative attitudes towards formalized smoking cessation interventions.

Conclusion: There ate many approaches to the smoking cessation process. Whether an attempt is successful depends more on individual conditions and the amount of commitment invested in the attempt than on the specific cessation strategy used.

Practice Implications: Future adolescent smoking cessation interventions should be flexible regarding both structure and content and should focus on the individual learning process, tather than adhering to rigid cessation strategies.

Word count abstract: 181

Word count main text: 4.542

Word count whole text: 5.758

Keywords: adolescence, smoking cessation, qualitative research, stage of changes, progtamme development 


\section{Introduction}

Every year many adolescents attempt to quit smoking (27). For instance, an annual survey among Danish youth showed that approximately $40 \%$ of all smokers had tried to quit at least once in the year preceding the survey (23). Quit attempts of adolescents, however, are less successful than quit attempt of adults (76), and there is a need for interventions supporting young people in their attempt to quit smoking.

Although some school-based intervention approaches have shown promising results (77), the majority of youth seems to be unwilling to join a school-based smoking cessation programme $(78 ; 79)$ or use nicotine replacement therapy (80), and most cessation programmes have had difficulties in recruiting adolescents for smoking cessation interventions (17). In general, adolescents consider interventions as patronizing, and something for older, addicted smokets $(19 ; 20 ; 81)$. Studies of adolescents' perception of effective cessation strategies reveal that most adolescents consider 'willpower' as the most important determinant of smoking cessation $(21 ; 81)$ and that they prefer either self-help programmes, friends' support or no help at all $(22 ; 82)$ then making a cessation attempt. Thetefore, a greater understanding of the adolescent smoking cessation process is necessary to develop interventions that are both effective, acceptable and accessible to youth $(71 ; 72 ; 82)$.

Many studies have described the adult smoking cessation process in terms of subsequent stages of change: precontemplation, contemplation, preparation, action, maintenance and relapse (83). Progression through these stages is thought to be mediated by processes which generally can be described as either 'behavioural' or 'cognitive'. Behavioural processes such as stimulus control or teinforcement management are the 'actions' that ate taken in a change process; cognitive processes such as consciousness taising or self-reevaluation should be seen as mental 'activities' that take place during the change process. $(83 ; 84)$.

Few studies have addressed the cognitive and behavioural strategies used by adolescents in their quit attempts. Studies among American adolescents showed that when compared to adults, adolescents tended to use action-orientated strategies rather than cognitive strategies in the stages preceding the actual quit attempt (precontemplation, contemplation, preparation) (84). A qualitative study among American adolescents found that they used several cognitive and behavioutal strategies to maintain smoking cessation, and that friends and family had a great influence on the individual's quitting intentions and possibility of successful maintenance (19).

Research on the predictors of smoking cessation suggests that success is positively related to a lower number of smokers among friends and family (36;39), and perceived social support (36). Research further suggests that those 
Events for Adolescent Smoking Cessation

who smoke in order to cope with stress or negative feelings are less likely to quit successfully (47).

As a precursor for later intervention development, this study aimed to explore the smoking cessation process among Danish youth. The main research questions were 1) Which cognitive and behavioural strategies do adolescents use in their attempts to quit smoking? 2) Which attitudes and beliefs do adolescents have towards the process of smoking cessation and smoking cessation interventions? 


\section{Methods}

\subsection{Study design}

We conducted a qualitative study among former daily smokers whom all tried to quit smoking on the 1 st of January 2004. Six group discussions and four in-depth interviews were held in the four largest towns in Denmark, during April-May 2004 , corresponding to 45 months after the quit-date. Interviewees were grouped as either ex-smokers or current smokers and interviewed separately. Under Danish law the study did not need ethical approval.

\subsection{Sample}

The interviewees were recruited from participants in the Danish Cancer Society's internet/SMS/email smoking cessation competition for young people (Quit \& Win), held in January 2004 [Reference in production]. A total of 485 adolescents were contacted of whom 65 tesponded (13.4\%) and 34 signed up for the interview. Since six individuals did not show up for the interview, the study finally comprised 26 participants: 18 smokers (failed to quit) and 8 ex-smokers (succeeded in quitting). 'Table 1 shows a profile of the participants. Daily cigarettes smoked before the quit attempt were 14.8 cigarettes for current smokers and 14.0 for ex-smokers. Mean age was 16.9 years for the smokers and 17.8 yenrs for the ex-smokers. The mean age of smoking debut was 13.3 years for current smokers and 13.5 years for ex-smokers and the experience of social support on a scale from 1-5 was 3.6 for smokers and 3.8 for ex-smokers. Except for smoking status there were no major differences between the groups.

'The authors confirm all petsonal identifiers have been removed or disguised so that the persons described are not iclentifiable and cannot be identified through the details of the story. 
Table 1: Profile of participants

\begin{tabular}{|c|c|c|c|c|c|c|c|c|c|c|}
\hline 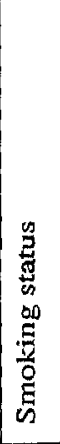 & 蓆 & 案 & 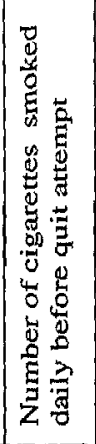 & 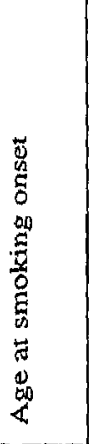 & 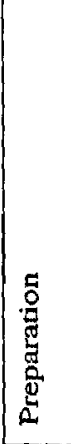 & 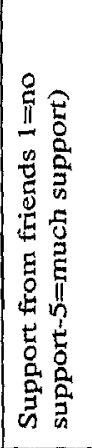 & 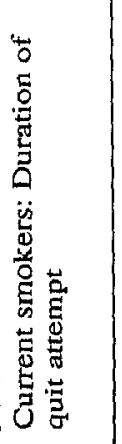 & 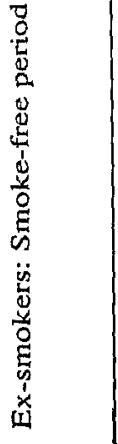 & 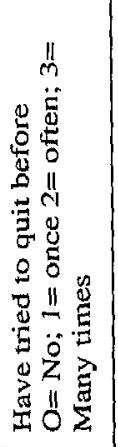 & 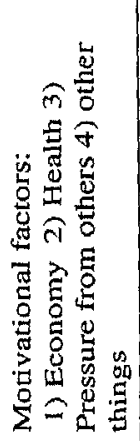 \\
\hline \multirow{18}{*}{ 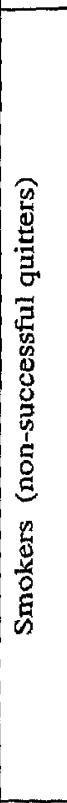 } & Male & 16 & 15 & 13 & yes & 5 & 20 days & & 1 & $1 ; 2 ; 3$ \\
\hline & Male & 17 & 12 & $\overline{13}$ & yes & 5 & 35 days & & 2 & 1 \\
\hline & Male & 19 & $20-25$ & 14 & $?$ & 3 & 1 day & & 3 & $1 ; 2$ \\
\hline & Male & 19 & $15-20$ & 14 & No & 3 & 30 days & & 2 & 2 \\
\hline & Female * & 15 & 5 & 9 & No & 3 & $\begin{array}{l}5-6 \\
\text { months } \\
* *\end{array}$ & & 2 & 3 \\
\hline & Female & 15 & 20 & 13 & No & 3 & 10 days & & 0 & $1 ; 3$ \\
\hline & Female & 15 & 10 & 13 & No & 4 & 5 days & & 1 & 2 \\
\hline & Femalc & 17 & 10 & 15 & yes & 3 & 14 days & & 2 & 3 \\
\hline & Female & 17 & $5-10$ & 15 & yes & 5 & 8 days & & 2 & $2 ; 3$ \\
\hline & Female & 17 & $10-15$ & II & yes & 1 & 31 days & & 2 & $1 ; 2$ \\
\hline & Female & 17 & $29-30$ & 13 & No & 3 & 1 day & & 2 & 1 \\
\hline & Female & 18 & 17 & 17 & $?$ & 4 & 10 days & & 0 & $1 ; 2$ \\
\hline & Female & 18 & $10-20$ & $12-13$ & yes & 3 & 40 days & & 2 & $(2) ; 4$ \\
\hline & Female & 18 & 15 & 11 & No & 3 & 3 months & & 2 & 4 \\
\hline & Female & 19 & 20 & 12 & No & 4 & 2 days & & 2 & $1 ; 2 ; 4$ \\
\hline & Female & 19 & $10-15$ & 12 & No & 4 & 14 days & & 2 & 4 \\
\hline & Female & 19 & 10 & 17 & No & 3 & 5 days & & 1 & 2 \\
\hline & Female & 20 & 20 & 15 & No & 5 & 30 days & & 1 & $1 ; 2$ \\
\hline \multirow{8}{*}{ 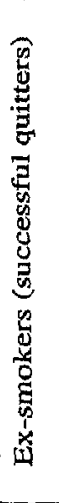 } & Male & 17 & 15 & 12 & No & 5 & & 4 months & 2 & 2 \\
\hline & Male & 18 & 10 & 14 & $\mathrm{No}$ & 2 & & $\begin{array}{l}4 \\
\text { months }\end{array}$ & 0 & 1 \\
\hline & Male & 18 & $5-10$ & 15 & $?$ & 4 & & 50 days & 1 & 1,2 \\
\hline & Male & 20 & 20 & 14 & No & 5 & & $\begin{array}{l}>4 \\
\text { months }\end{array}$ & 2 & $2 ; 4$ \\
\hline & Female & 15 & 15 & 10 & yes & 3 & & 30 days & 2 & $2 ; 3$ \\
\hline & Female & 17 & 13 & 12 & No & 3 & & $\begin{array}{l}>4 \\
\text { months }\end{array}$ & 2 & $1 ; 2 ; 4$ \\
\hline & Female & 17 & $15-20$ & 14 & No & 3 & & \begin{tabular}{|l|}
$3-4$ \\
months \\
\end{tabular} & 2 & $1 ; 2$ \\
\hline & Female & 21 & 15 & 17 & No & 5 & & $\begin{array}{l}4 \\
\text { months }\end{array}$ & 0 & 1 \\
\hline
\end{tabular}

*Did not participate in the competition (came with a friend).

**P revious quit attempt (not in connection with the competition).

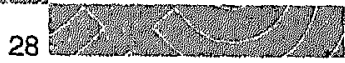




\subsection{Measurements}

Data were collected from three sources: 1) The enrolment procedure of the competition provided data about amount smoking before cessation; 2) a short questionnaire completed immediately before the interview provided data about present smoking status, smoking history, perceived social support during quit attempts (on a 5-point Likert scale), and educational/work status; and 3) semi-structured qualitative individual- and group interviews ptovided insight and knowledge about the adolescent quitting process. This paper focuses on results from the semi-structured interviews. 'The interview guide was developed using theoretical constructs from the Transtheoretical Model/Stages of Changes (83), Social Cognitive Theory (85) and key findings from the literature. The interviews addressed: smoking history, motivation to quit, self-efficacy, preparation to quit, identification and coping with difficult situations, motivational change during the cessation attempt and perceptions of cessation interventions.

\subsection{Procedure}

All participants aged 15-20) who were daily smokers when they entolled in the competition were contacted via email and SMS and requested to participate in the study. As compensation for time and travel costs the participants were offered teimbursement of travel expenses and two cinema tickets. All responders received a petsonal call with practical information about the interview. The main reasons for not consenting to participate were geographical distance and time constraints due to examinations.

Before the interviews, participants were informed in writing that the participation was voluntary and that data would be treated confidentially. At the start of every interview, participants were informed they were not obliged to answer all questions. The group interviews were conducted by two experienced interviewers - a discussion leader and an observer - with a background in health promotion, the in-depth interviews by one interviewer. $\Lambda$ fter each interview, the interview guide and the procedures were evaluated and adjusted if necessary.

\subsection{Analysis of data}

The analysis of data followed the procedures from Kvale 1996 (86): First, we established central categories and subcategories for all central statements after examination of two interviews with current smokets and two with ex-smokets. Subsequently, all interviews were read and coded according to the approptiate categories. When central statements did not fit the original categories, new categories were established. Second, we selected statements about preparation for quitting, the quitting process, coping strategies, factors influencing cessation and attitudes towards cessation interventions. In the further analysis we condensed the statements by abridging the meanings expressed by the interviewees into 
Events for Adolescent Smoking Cessation

shorter formulations, and organised data into categories in order to compare subgroups. We compared the statements from the successful quitters with the current smokers to identify differences regarding use of strategies and attitudes towards the quitting process. We further tried to establish a general description of the adolescent smoking cessation process that was valid fot both groups. In relevant cases we interpreted the findings in relation to the 'Stages of Changes' from the Transtheoretical Model (83). 


\section{Results}

\subsection{The youth smoking cessation process}

This section describes the adolescent smoking cessation process in terms of stages of change: preparation, action and maintenance.

\subsubsection{Before the quit date (preparation)}

"I didn't worry alout the quitting; I just thought I would stop" "I didn't really prepare at all. I just began to tbink before I smoked"

Our interviews suggested that the interviewees had very different views on the concept of 'preparation', and only about half had prepared before the quit day (see figure 1). Among those who had not prepared, some indicated that they did not like the idea of active preparation and that "behavioural change had to come from the inside'. In their view behavioutal change should come from an 'inner emotional drive', something that does not fit with planning and prepatation. Others stated that they had not considered pteparing their cessation attempt at all, and that they had stopped smoking on the day they had the urge to quit. 'This indicates that some considered cessation as something you do and not something you prepare for: You do not know what it will be like when you quit. It is needless to prepare, you just have to do it.

\section{[Before the quit date] "I tried not to smoke at school"}

Among the adolescents' who indicated to have made some preparation, some were actually unaware that they had prepared before their cessation attempt, while others had prepared themselves intentionally. The most common preparation strategy was minor behavioural cessation experiments such as not smoking at school or work, reducing cigatettes by one a day, and only smoking cigarettes from others. These actions can be seen as a way to create small successes and thereby building up self-confidence before the actual quitting. The second most frequently mentioned strategy was informing friends and family about quitting intentions. In this way participants both teduced possibly social bartiers and created social support for future situations with cigatette cravings. Other examples of preparation strategies that were tevealed in the interviews were: establishing incentives, wotking with decisional balance by writing down advantages of quitting and/or disadvantages of smoking; planning how to cope with difficult situations, for example by deciding not to socialise with friends in breaks or substituting cigarettes with fruit or sweets in difficult situations; gathering information about smoking cessation, for example by asking health professionals, friends, family or by searching the Internet. 
Figure 1: Different approuches tomards the period before llen quit datt.
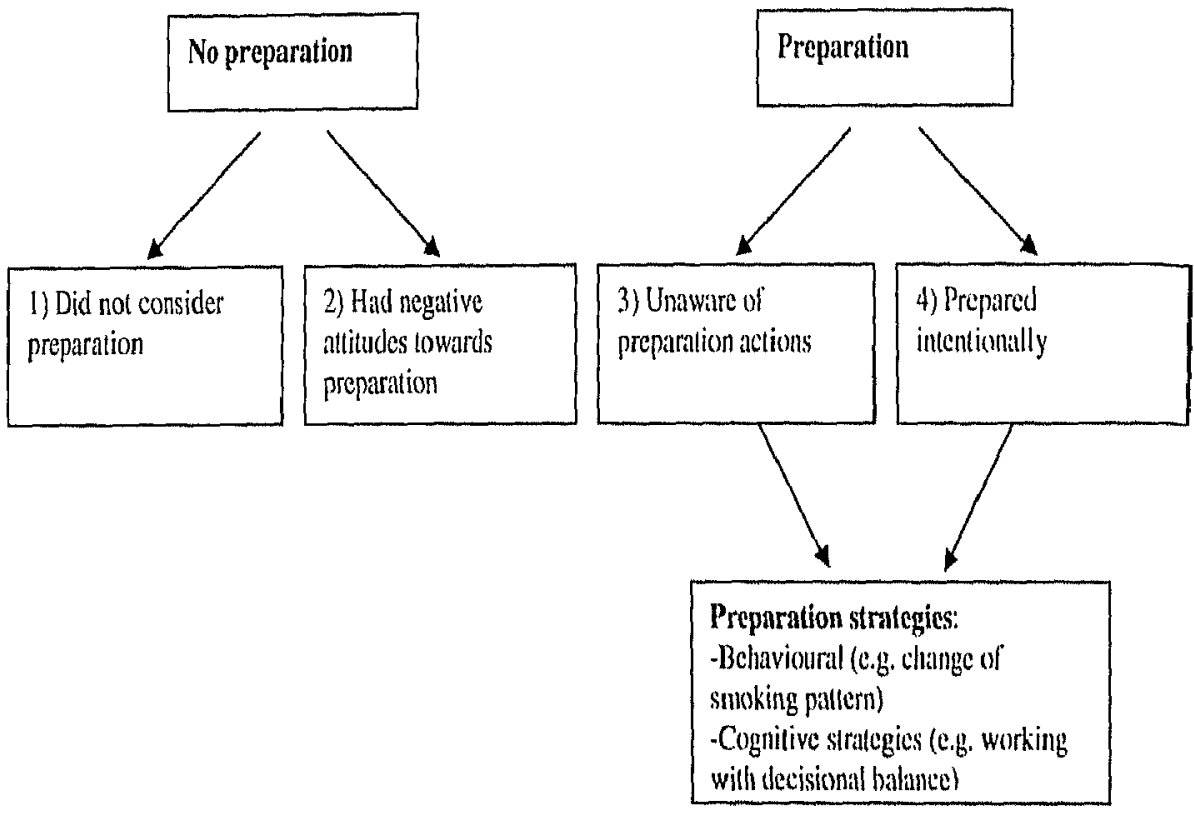

\subsubsection{Quitting (first days of action)}

As our subjects patticipated in a smoking cessation comprtition with a lixed quit date (01.01.2004), we could examine the way they approached the period immediately after the quit date. We identified two styles: the 'roder' style and the 'learning by doing' style. Individuals following the 'tosice' style stopped on the fixed quit date and tried to mantain their cessation atrempt as long as pussible. This group followed the usual 'track' of cessation and fitted well into the competition concept.

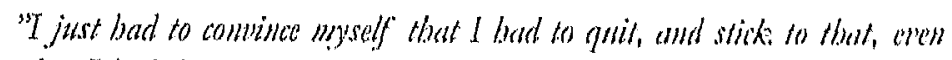
when I bad the urge to smoket"

In contrast, the 'leatners' experienced a short period with minor relipses, before embarking on a more lasting cessation attempt. Iike the behavioural experiments before quitting these minor relapses were used to develop skills to cope with bat:tiers in the cessation attempt which, in turn, enhanced self-efficancy (see figure 2). 
Figure 2: Different approathes toments the first doys of quitting.

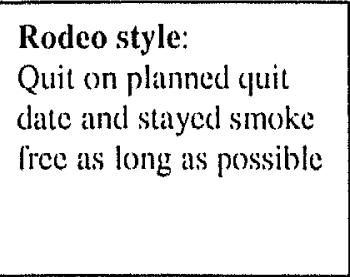

\author{
Learning by doing: \\ Had several minor quit \\ attempts before a \\ longer and more \\ committed attempt \\ took place
}

\subsubsection{Coping strategies in difficult situations (action/maintenance)}

All interviewees agreed that cigarette craving came in waves, often triggered by specific circumstances. 'lhe cravings were worst in the lirst weeks atter the cuitting. In general, social situations involving alcohol consumprion seemed the hatdest to overeme. Also brealss, boredom, compurer work, habitual situations (c., in the morning or atter dinner), and psychologically diflicult situations (stress, sadness) were mentioned as situations triggering craving.

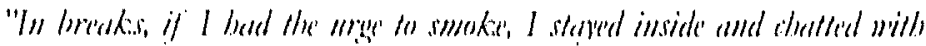

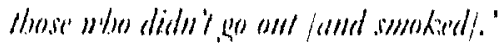

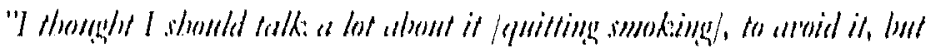

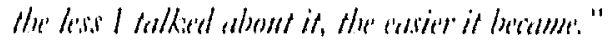

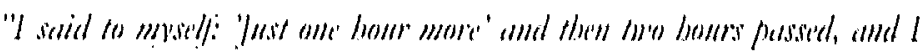
forigent alloum it."
}

When losking at how the adesescents either avoided or mantaged cigarete crat ving, the intervicus suggested three catcegries of coping strategies: 1) A lirst caregory can be referted to as 'cognitive copping'. Some participants' statced that they deliberatcly hatel focussed on positive experiences unrelated to smoking (1) thers mentioned that they hat focussed on the aldvantages of yuitting or the disadvantages of smoking. () ther congnitive copping strategies that were mentioned were deliberately avoiding thinking abour snokingr. 2) Belavioural coping were actions that cither replated smoking with something else such as eating truits or sweets and drinking water, or actions that distracted the person from cigaterte craving. 'The bater included, for instance, engiging in physical exercise, leaving the table immediatedy atter dinner, averiding socialising with smoking firends, or, when at a club, (o) avoid smoking cravings by dancing instead of hanging at the bar , 3) (On the interpersomal level strategies were about atranging social suppore in calse of cravings or emotional imbalances and setting up agreconents about refinining from cigarette ofters (sec ligure 3 ). 
Figure 3: Different coping strategies.

\begin{tabular}{|l|}
\hline Cognitive \\
-Avoiding thinking of \\
smoking \\
-Focus on positive \\
experiences unrelated \\
to smoking \\
Focus on advantages \\
of quitting \\
\hline
\end{tabular}

Behavioural
- Replacement
of cigarettes
- Avoiding situations
with craving

Interpersonal

-Social support in situations with craving Arrangements about refraining from cigarette oflers

The use of coping stmategies seemed partly to depend on situations and conditions but also varied between persons, even in similar trigger situations. We did not find a difference in coping strategies between the successful and unsuccess ful quitters.

\subsubsection{Relapse}

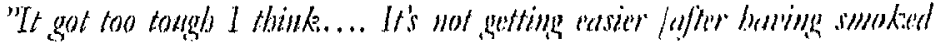
oncel".

At the time of the interview, 18 of the 26 interviewees had re-indiated smoking. Again, different approaches towards this 're-initiation process' were iclentilied. A first group of quitters had managed to quit for only a few chays. In the interviews, these participants acknowledged that they had mot seriously tried to quit, and that they currently lacked motivation to quit. Among those who managed to stay smoke-ftee for a longer petiod, some mentioned to experience cessation as a daily struggle that did not diminish with time. At a certain point (sometimes after one month) they deliberately te-initiated smoking. like the first group, they indicated to lack the motivation for another cessation attempt in the near future. A thitd group revealed that they had managed to quit because of a strong motivation, until they had an unplanned relapse at a social event. Subsecuently, they had gradually te-initiated smoking without making a deliberate decision to do so. This group regretted having telapsed and was motivated to give it at another try.

"T thought OK I an an occasional smoker. I thought I could kieep it that way, but I couldn't".

Almost all participants who failed in their quit attempt, attributed their, relapses to a lack of motivation, which again was associated with lack of willpower. Lack of coping skills was not mentioned as the renson for not maintaining cessation. 


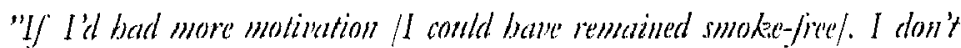
think. that people around me, or tbings, conld bane made any difference".

\subsection{Factors influencing cessation}

In this section we describe factors that could be considered to influence the smoking cessation process.

\subsubsection{Commitment}

Although the interviewees had different ickeas about and approaches terwards the cessation process, they generally agreed that it was necessary to be "motivated" or "to bav millpomer" to quit. "These ideas are incorporated in the word "commitment', which, here, is defined as the amount of energy an individual is willing to invest in the quit attempt. The committed yuitter expressed willingness to invest energy, or malse sactifices to lecome smoke-free. Committed yuitters had "quitting histories' indicating that they had expericneed difficult situations and that they had put effort into the attempt. By cloing so they involved themselves in a learning process in which their problem solving and coping competencies were extended which in turn increased their selfeeflicacy. 'This can be described as at self-regulatory process(85) with in thece-step learning circle: 1) They identified difficult situations; 2) they rested one or mote coping strategies; 3) they evaluated and (if necessary) modilied the strategies. In addition, committed puitters seemed to be motivated by internal factors, such as negative health experiencess and fear of long-term health consequences.

Conversely, the intervicws suggested that uncommitted quitters had not mate concerted effort en cuit, and that they were unwilling to make sacritices. The cessation atcempts of these participants typically ended atter only a few days and in two cases alter unly a few hosurs. Uncommited quitters did anot try on test different strategies tos overeome difficult situations, and most of them were motivated by external facters, such as saving money, or featr of parents' reaction.

All successful quitters had 'yuirting historics' that indicated initially strong commitment towards the cessation attempt, whereas the pattern among the unsuccessful quitters was mixed. Heswever, commitment alone seemed to be insulficient to guarantec sucesss. 'I'he unsucesssful quiters gave many examples of quitting histories indicating that an initially strong commitment may fade awaly' for different reassons. Both experiences of negative side effects of smoking cessation, such as weighe gain or craving symptoms that do not diminish over time, may negatively affect commitnent, whereas inproved lieness, increased offactory sense, improved respiration and financial savings, increased commitment. All in all commitment should be seen as a necessity when initiating the cessation 
process. Commitment is a prerequisite for engagement in the necessary learning processes that makes one believe that success is achievable.

"After the magic seven days, I got a pat on the shoulder... Affer sezen doys I betieved I could quit"

\subsubsection{Environmental influences}

The patticipants reported that external factors affected the success of smoking cessation attempts. Most stated that smoling friends hampered cussation main tenance. The attitude of friends towatds cessation, and a smoke-free school policy were also mentioned as important. One participant mentioned viewing smoking in movies as an external factor that hampeted remaining smoke-firee.

\subsubsection{Cessation interventions}

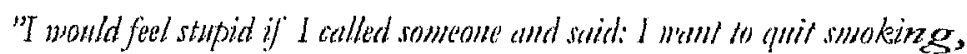
belp me".

The interviewees had negative attitudes towards the iden of ccisation interventions in general. Many expected the formalized external support to be patronizing and incapable of understanding the actual situation of young perple: smoking cessation was seen as a matter of willpower and motivation, and no one could identify with persons who would contact a professional counsellor for support. This was regarded as something done in the case of alcohol or drug diependency, and considered irrelevant for smoking cessation. However, several were positive towards their experiences with the smoking cessation comperition, and mentioned the easy access via SMS/Internet and the clance of winning in price as reasons for their positive attitudes. 


\section{Discussion and Conclusion}

\subsection{Discussion}

The aim of this study was to identify strategies and approaches used in the adolescent smoking cossittion poroess. The main finding was that adolescent smolsing cessation must be seen als an individual process and that all stages in this process are characterized by a broul vartety of quit and maintenance strategies. We could nore ickentify a superien strategy that could explain success, but found that success was related on whether or not the cuitter was committed to a learning process in which difterent strategies were rested, evaluated re-tested et ceterat.

Nheout halt of the interviewees prepared for the gut attempt, whereas the other half tricel guitting with litte or no consideration beforehand. In the group who prepared, the strategies focused on reducing hartiers, creating positive experichces, creating social support, increasing motivation to yuit and increasing know-

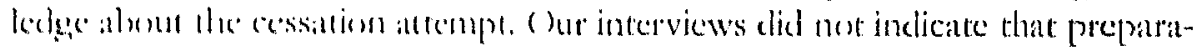

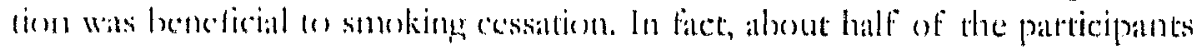
havingr sucreceled in quitting smoking reported that they had not made any pre-

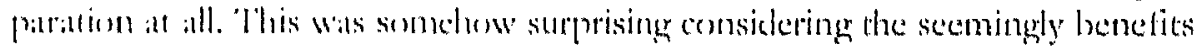

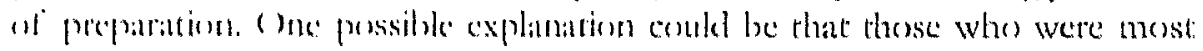

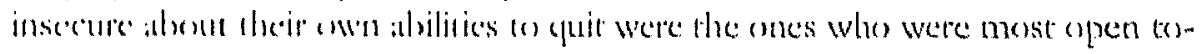

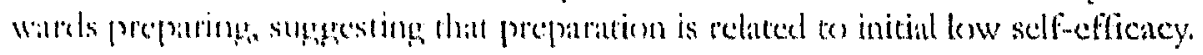

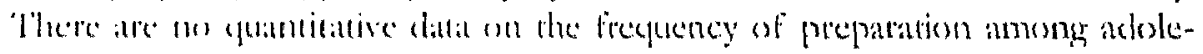

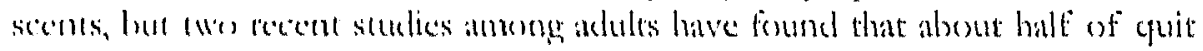
allempes "wete unkertiken withur preparation (87;88), suggesting that the unprepared cessation antemper is likely to be common among adokescents as well.

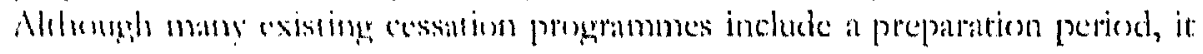

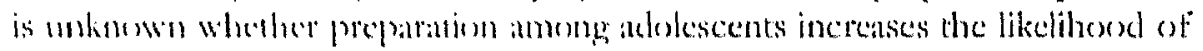

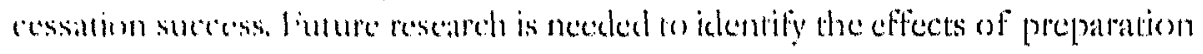

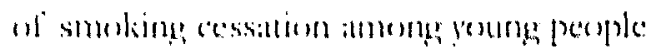

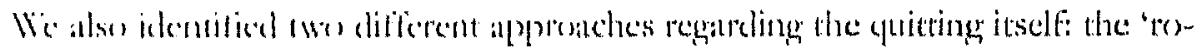

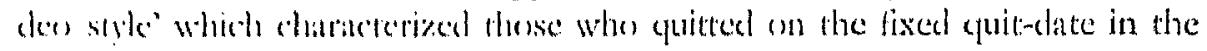

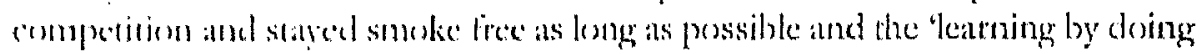
strke" which characterizel these who hat an series of relapsess after the actual quit date. In the latter style mimer telapses were used on develop coping skills to

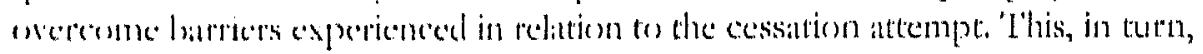

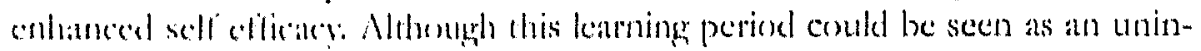

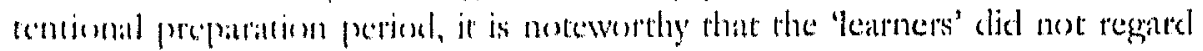

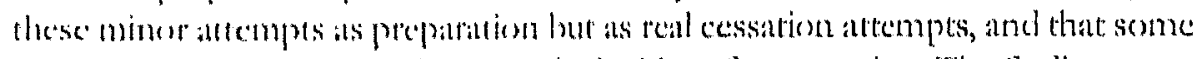

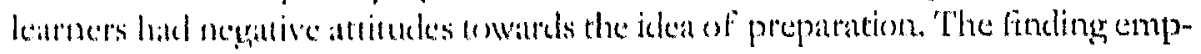
hatsises that interventeons with the concepte preparation - yuitting - mantenanes may he problematic, since in group of quiters needs a cessation concept with a 
flexible quit-date. It is a challenge for future interventions to include this cessation/change approach, since it makes high demands on the level of interaction and tailoring.

Overall we identified three coping strategies used as part of the cessation attempt: cognitive, behavioural or interpersonal. We found no clear differences in the coping styles used between the successful and unsuccessful quitters and we found that different individuals may use different coping strategies, even when situations that trigger cravings are very similar. This indicates that recommending a specific strategy to handle a specific problem is rather problematic. Problems with cravings and relapses can be approached in many ways, and whether an individual finds a specific strategy relevant and effective largely depends on individual conditions (e.g. the number of smokers in the social environment, type of dependency or number of days since cessation). However, it is important that quitters engage in a leatning process where they test different coping strategies and find their own way through their quitting process.

Although the interviewees recognized that the cooperation of smoking friends, in particular, and support in the social environment were important to avoid relapse, 'willpower' was considered as the most important determinant of smoking cessation. This result mirrors the results of other studies $(21 ; 81)$. Furthermore, like othets, we found that adolescents expect cessation interventions to be patronizing and regard seeking support for an internal personal process as extreme $(19 ; 20 ; 81)$. These results suggest that formalized smoking cessation programmes might expect recruitment problems. However, since the participants did sign up and participated in the smoking cessation competition, there were a discrepancy between their negative perceptions and their concrete actions. Our interpretation is that the intervention concept had some characteristics that overruled negative perceptions: 1) Easy access via both mobile phones and the Internet made the support available in settings close to youth culture; 2 ) the chance of winning an attractive prize, which gave a motivational incentive, and an internal and external argument for participation other than lack of willpower or need for help; 3) finally, they did not have to confront others with their cessation attempt and lose face in case of relapse. These findings suggest some of the recruitment problems experienced in formalized adolescent smoking cessation programmes $(78 ; 79) \mathrm{can}$ be solved, if we put more emphasis in designing the interventions to fit adolescents needs and perceptions.

The study is subjected to several limitations. Attrition was high with only about $5 \%$ of the participants from the smoking cessation competition attending the interviews. Although participants came from both urban and rural areas, from different parts of Denmark, from different age groups, from different educational backgrounds and from both sexes, they cannot be considered a representative sample of Danish youth. Both long journey times and insubstantial reward for 
attending the interviews probably influenced participation. Therefore, interviewees must be considered more interested in learning about their quitting attempt, and are probably more positive towards smoking cessation, than those who did not respond. Furthermore, all interviewees participated in a smoking cessation competition. This selection criterion enabled us to interview a group of adolescents who initiated their quit attempt on the same date, but it probably also biased the study in several ways: 1) The interviewees must be considered more motivated to quit than the general youth smoking population. We might have overlooked strategies used by people with low motivation and involvement, and it is likely that the 'uncommitted cessation attempt' is much more prevalent in the general population than found in this study. 2) The intervention probably raised awareness among the interviewees so that they appeared more conscious and reflective about the cessation process. 3) The cessation intervention had some educational elements regarding preparation, motivation and coping that might had led to uniform perspectives regarding the cessation process, and a more positive attitude regarding cessation interventions. Therefore, this study cannot be used to estimate the prevalence of the expressed opinions in the general population. In addition, particularly the low number of ex-smokers in the study made it difficult to identify differences between the groups.

However, the purpose of the study was to identify cognitive and behavioural approaches and strategies towards the youth smoking cessation process. The limitations of the study do not threaten the main finding: the identification of both great individual and group variance regarding approaches and strategies. In fact, a more representative (and more diverse) sample would probably have revealed an even greater diversity. When we look at results regarding adolescents' views on the smoking cessation process and smoking cessation interventions we see the same picture. Therefore our findings that 'willpower' is perceived as the most important determinant of smoking cessation, and the negative expectations towards formalised smoking cessation are likely to occur in the general adolescent population too.

\subsection{Conclusion}

Our results recommend caution when suggesting a specific method, strategy or approach regarding adolescent smoking cessation. There are many approaches to the smoking cessation process and whether an attempt is successful seems to depend more on individual conditions and the amount of commitment invested in the attempt than on the specific strategy used.

\subsection{Practice implications}

Future interventions should be flexible regarding both structure and content. We recommend that interventions are designed to stimulate a positive learning circle where coping, commitment and self-efficacy are developed in a self-enhancing 
process. Further, programmes should be appealing and not patronizing, be easy to participate in, and have a motivational or incentive element. In addition interventionists should not only focus on conventional settings but also explore possibilities for intervening via peer-group support and in settings like youth clubs, the Internet, SMS. Finally, adolescents who believe that 'willpower' is the only key factor for successful smoking cessation are unlikely to participate in cessation programmes. Therefore, it is important to communicate that many other factors such as skills to cope with cigarette craving and skills to obtain social support can facilitate a successful cessation attempt.

Future research should focus on identifying communication channels/platforms that can not only facilitate the necessary learning processes, but can also be expected to be generally used by adolescents.

\section{Acknowledgements}

This study was funded by a grant from the Danish Ministry of the Interior and Health. The funding sources had no influence or involvement in the making of this research paper. 
3 Intervention development 
Events for Adolescent Smoking Cessation 


\title{
The Development of an Adolescent Smoking Cessation Intervention - an Intervention Mapping Approach to Planning
}

\author{
Peter Dalum MA*, Hetman Schaalma, PhD** \& Kok Gerjo, PhD** \\ Submitted for publication \\ *Dept. of Prevention and Documentation, Danish Cancer Society \\ **Maastricht University, Dept. of Work \& Social Psychology
}

Running head: Adolescent smoking cessation intervention

Keywotds: intervention mapping; program planning; adolescent; youth, smoking cessation, cancer prevention

Cotrespondence should be addressed to:

Peter Dalum, Department of Prevention and Documentation, Danish Cancer Society, Strandbldv. 49, DK-2100, Copenhagen, Denmatk 


\section{Abstract}

Objectives: The objective of this project was to develop a theory and evidencebased adolescent smoking cessation intervention using both new and existing materials. This paper does not present evaluation data.

Methods: We used the Intervention Mapping (IM) framework for planning health promotion programs. Based on a needs assessment we identified important and changeable determinants of cessation behaviour, specified change objectives for the intervention program, selected theoretical change methods for accomplishing intervention objectives, and finally operationalized change methods into practical intervention strategies.

Results: We found that guided practice, modelling, self-monitoring, coping planning, consciousness raising, dramatic relief and decisional balance was suitable methods for adolescent smoking cessation. We selected behavioural journalism, guided practice and Motivational Interviewing as strategies in our intervention. Contusion: Intervention Mapping helped us to develop a systematic adolescent smoking cessation intervention with a clear link between behavioural goals, theoretical methods, practical strategies and materials and with a strong focus on implementation and recruitment.

Practice implications: High transparency of the decisions taken in the development process with insight into both the overall goals of the intervention, the performance- and change objectives, and the theoretical methods and strategies used in the intervention design is crucial when designing health-promoting interventions.

Wordcount: Abstract:199; Main text: 4.027

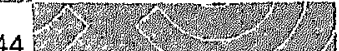


Intervention development

\section{Introduction}

Smoking is the primary cause of one third of all cancers and is responsible for about 14,000 annual deaths in Denmark (1). About $30 \%$ of all Danish adolescents smoke either daily or on a weekly basis. Every year, approximately $40 \%$ of all Danish smokers try to quit, but few manage to quit successfully (23). In the past years a growing number of adolescent smoking cessation interventions have emerged. To date, the evidence for effectiveness is rather mixed. Whereas some reviews conclude that smoking cessation intervention are effective (89), other conclude that we need additional evidence to draw conclusions about effectiveness $(71 ; 77)$. It is generally assumed though, that interventions based on a cognitive-behavioural approach ate most likely to be successful $(71 ; 77 ; 89)$.

A major challenge in smoking cessation is to get smokers to participate in the interventions. Among adults the median recruitment tate for participation in smoking cessation interventions is $2.0 \%$ (17). Various studies indicate that recruitment is also a challenge in adolescent smoking cessation. For instance, Leatherdale and colleagues found that $77 \%$ of Canadian adolescents planning to quit, preferred to quit on their own, and that Canadian youth have a rather negative perception about formalised smoking cessation interventions $(78 ; 82 ; 90)$. Backinger et al. estimated that recruitment rates in adolescent smoking cessation are between $2-10 \%(18)$. In addtion, a study of a Danish school-based smoking cessation intervention indicated that it might be be tather difficult to implement smoking cessation programs in schools (16). If we cannot overcome these problems, it is unlikely that smoking cessation programs will have a significant effect on adolescent smoking. Interventionists should therefote not only focus on effectiveness of future cessation programs, but also on recruitment and implementation issucs.

Intervention Mapping (IM) is a planning tool for the development of theory and evidence-based health promotion interventions that incorporates the anticipation of program adoption and implementation from the start of the development process (73). IM comprises six phases, each with clear tasks and a cleat end product (see Figure 1). Although Intervention Mapping is presented as a series of tasks, Bartholomew et al. see the planning process as iterative rather than linear, albeit cumulative. Program planners move back and forth between phases and tasks, but each phase is based on previous phases and inattention to a particular task may lead to mistakes and inadecuate decisions.

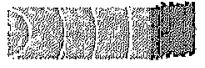


Figure 1: Protocol for the Intervention Mapping procedure. Source Bartbolemenw et al. (13).

$\begin{array}{|ll|}\text { Step 1 } & \begin{array}{l}\text { Plan needs assessment with PRECEDE } \\ \text { model }\end{array} \\ & \begin{array}{l}\text { Assess health, quality of life, behavior, } \\ \text { and environment }\end{array} \\ \text { - Assess capacity } \\ \text { - Establish program outcomes }\end{array}$

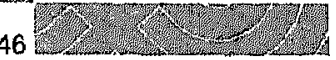


One of the key features of IM is that the mapping process leads to transparent descriptions of the decisions made during the intervention development process, demystifying the logic between program objectives, intervention strategies and their theoretical underpinnings. This transparency is crucial in order to gain insight into why some interventions are effective and other are not, but also for transferring experiences from one intervention context to another $(74 ; 75)$.

This article describes how we used the IM methodology to develop an adolescent smoking cessation intervention consisting of both new and existing materials. In addition, we will describe how IM was used to set up an implementation- and evaluation plan as part of the development process. The article does not include the results of program evaluation. 


\section{Methods and Results}

\subsection{IM Step 1: Needs Assessment \\ Method:}

At the start of the program development process we establised a planning group comprising interventionists and researchers from the Danish Cancer Society (DCS) and coordinators being responsible for smoking prevention at the local level. DCS lead the daily planning of the project; local coordinators were regularly involved in program planning. We started with a needs assessment to gather information about adolescent smoking cessation behaviour, the target group and the educational system. We conducted a pilot study of smoking cessation counselling in various Danish youth education settings. This study primarily addressed recruitment barriers and the implementation capacity of schools. We conducted a literature study focusing on identifying individual and environmental factors related to smoking cessation. We searched for scientific papers in PubMed and PsycInfo using the keywords "smoking cessation", "adolescence", "youth", and "quitting", and we selected longitudinal studies from Western Europe, North Ametica and Australia with a focus on determinants of smoking cessation. In addition, we identified examples of effective intervention studies. We included studies with at least 300 participants, a control group, a follow-up period of at least three months, and effects on smoking cessation. The studies were analysed with regatd to intervention content. Finally, we conducted a qualitative study among adolescents who had tried to quit smoking, focusing on the strategies they had used in attempts to quit smoking, and on their attitudes and beliefs towards the process of smoking cessation and smoking cessation interventions. The outcomes of this needs assessment served as an evidence base for the goals of our intervention program.

Results:

1) Pilot study

In collaboration with local coordinators, we conducted a study on the feasibility of a comprehensive program including five group counselling sessions for students aged 16-20 in three different youth education settings (16). After program implementation we interviewed students, counsellors, school leaders and cootdinators with regard to satisfaction with the program, barriers for recruitment among the students and barriers for implementation at the schools.

We found that only a minority of the smoking students was interested in participating in the progtam. When the program was implemented during school hours, we managed to recruit about $5 \%$ of all daily smokers. When the program was implemented after school hours, we were not able to recruit sufficient participants to run the counselling sessions, even in schools with more than 500 smokets. In addition, the study revealed that schools were rather reluctant to to implement 
the program during school hours, mainly because of an overloaded teaching program. Other implementation barriers were the incompatibility of the program and the class structure with the majority of students being non-smokers, and the lack of interest in participation among smoking students. Schools, however, expressed positive attitudes towards using the school as a setting for smoking cessation programs, as long as such progtams would not coincide with teaching hours.

In addition to the comprehensive counselling program, we tested an event-based minimal intervention concept including a 'cessation stand' with two counselors offering $\mathrm{CO}$ measurements, short one-to-one counselling, and a range of written materials regarding smoking and smoking cessation. This intervention tan during school breaks and lunch hours. This event-based intervention concept seemed to be far more popular among students than the comprehensive program; in some cases over $50 \%$ of smoking students participated in the events. We also found that a number of students received the short counselling more than once. We did not test the effect of the short counselling, but among adults minimal counselling provided by general practitioners has been found to have a small effect on smoking cessation (91).

Based on the outcomes of our pilot study, we concluded (1) that a conventional comprehensive smoking cessation strategy would interfere with widespread implementation, both on the individual and the school level, and (2) that a minimal event-based intervention approach would be mote easy to implement in a large number of schools, and would have more potential for recruiting a substantial part of the smokers.

\section{2) Literature review}

Our review of the literature on determinants of adolescent smoking cessation revealed that quitters, compared to the continuing smokers, have clearer intentions to quit smoking $(27 ; 39 ; 43)$, have higher self-efficacy expectations regarding quitting (39;51), are more likely to perceive the negative health consequences of smoking as personal relevant $(53 ; 55)$, have more academic success $(25 ; 35)$, have less psychological and social problems $(36 ; 52)$, are less likely to smoke to cope with psychological problems $(27 ; 47)$, smoke less $(25 ; 27 ; 47)$, have smoked for a shorter period of time $(35 ; 51)$, are less addicted to nicotine (47;57), associate with fewer smokers $(25 ; 31 ; 34 ; 35 ; 43 ; 44)$ and experience mote social support for cessation (36).

We also searched the literature for studies on school smoking policies, the accessibility of cigarettes, and the pricing of cigarettes. Although these factors have been shown to be related to smoking in general $(92 ; 93)$ we could not find any empirical evidence that these factors were relevant for adolescent smoking cessation. 
This literature suggests that both intra- and interpersonal factors are associated with adolescent smoking cessation, and that factors like coping skills, self-efficacy, individual health relevance, and social support are all relevant for cessation interventions.

3) Content analysis of effective adolescent smoking cessation interventions We identified two papers which met our selection criteria: 'Not On Tobacco' (60) and 'Project X' (62). Both interventions were based on a cognitive-behavioural approach. The 'Not On Tobacco' program focused on: Motivation, stress management, preparation for stopping, understanding and management of social pressure (both social and from media), and skill building. In Project $\mathrm{X}$ the focus was on: Motivation and decisional balance, knowledge of the harmful contents of cigarettes, management of stress, anger and immediate problems after quitting, insight in the decision-making process regarding quitting and the actual quitting process, and maintenance strategies (including weight control and focus on other behaviours).

Based on this content analysis we concluded that both motivation enhancement techniques and the development of coping skills for both individual and social situations should be crucial components of adolescent smoking cessations programs.

4) Qualitative study

Adolescent smoking cessation was further investigated in a qualitative study (94). This study suggested that adolescent smoking cessation is an individual process, and that a broad variety of coping strategies is used in all smoking cessation stages. We could not identify a single coping strategy being superior in explaining successful cessation, but we found that success was telated to whether or not the quitters were committed to a learning process in which different strategies were tested, evaluated, re-tested, et cetera. This suggests that futute interventions should be flexible regarding both structure and content, and that interventions should stimulate a positive leatning circle in which coping, commitment and selfefficacy are developed in a self-enhancing process. Further, programs should be appealing to youth, not patronizing and easy to attend, they should include a motivational or incentive element, and they should not only focus on conventional settings but also explore possibilities for intervening through peet-group support, or other alternative settings like youth clubs, the Internet, SMS, et cetera.

\section{Program outcomes}

All in all, we concluded that there is potential for implementing an effective school-based adolescent smoking cessation intervention in Denmark. Such an intervention should have the potential to be implemented in a least $90 \%$ of the schools, to reach over $30 \%$ of daily smokers, and to increase the annual quit rate 
from $5 \%$ (the estimated quit rate among smokers who do not receive support) to $10 \%$.

When implemented in all Danish schools, this would reduce the adolescent smoking rate with about $1.5 \%$, about 3,600 adolescents in the age-group of $16-20$ year olds.

\subsection{IM step 2: Programme Objectives \\ Method}

The second step in $I M$ concerns specifying program objectives. The first task is breaking down general health promoting goals and defining objectives targeting specific sub-behaviours: 'performance objectives' (PO). POs refer to subbehaviors or preparatory behaviours that enable the health promoting behaviout.

Results

Since our needs assessment suggested that successful smoking cessation was related to high motivation and commitment, high self-efficacy and strong coping competencies, we defined objectives for strengthening quitters tegarding these conditions. The Transtheoretical Model (83) and Self-Regulation Theory (95), both suggesting specific actions needed to reach health goals, guided the specification of a primary set of objectives. This primary list was validated among both experts and practitioners with experience in adolescents smoking cessation. Our final list of objectives is summarized in Table 1. 
Events for Adolescent Smoking Cessation

Table 1: Performance objectives for smoking cessation for adolescent smokers

Decide to quit

Decide to make a committed effort to quit

Prepare coping plans*

Quit smoking

Identify trigger situations

Make/perform coping plans*

Evaluate and adjust coping strategies

* We advise students to prepare coping plans before they quit, but since many adolescents quit without preparation the preparation of coping plans often occurs after the actual quit-date.

Once performance objectives were specified, we returned to the needs assessment outcomes to identify psychosocial behavioural correlates that were deemed both relevant for the purpose of our program and changeable. Assessments of importance we based upon our review of studies on the correlates of smoking cessation; assessments of changeability on general insights about behavioral change and the results of adolescent smoking cessation progtam evaluations (72;73;89;96); See Table 2. 
Intervention development

Table 2: Cognitive and social determinants identified in the needs assessment

The judged importance (I) and changeability (C) were used to select determinants for the matrix.

\begin{tabular}{lrc}
\hline Cognitive determinants & Importance & Changeability \\
\hline Knowledge* & + & ++ \\
Self-efficacy* & ++ & + \\
& ++ & 0 \\
Attitudes* & ++ & + \\
Academic skills & + & 0 \\
Coping skills & ++ & +
\end{tabular}

Social determinants

Number of smokers in social environment

$++\quad 0$

Social support for smoking cessation*

$++$

* Determinants included in the matrix.

Subsequently, we further specified program objectives by creating a matrix of change objectives. This matrix was created by crossing the performance objectives with the psychosocial correlates (Figure 1). For each cell one or more change objectives were defined, specifying what program participants need to learn to accomplish the performance objective. 
Events for Adolescent Smoking Cessation

Figure 2: Tbe matrix of performance objectives, determinants and change objectives.

\begin{tabular}{|c|c|c|c|c|c|}
\hline $\begin{array}{l}\text { Determinants } \\
\text { Performance } \\
\text { objectives for } \\
\text { adolescent } \\
\text { smokers }\end{array}$ & Knowledge & Attitudes & Self-efficacy & Skills & $\begin{array}{l}\text { External: } \\
\text { Support from } \\
\text { friends in near } \\
\text { social environ. } \\
\text { nent }\end{array}$ \\
\hline $\begin{array}{l}\text { Decide to quit } \\
\text { smoking }\end{array}$ & $\begin{array}{l}\text { Recall ressons for } \\
\text { stopping smoking }\end{array}$ & $\begin{array}{l}\text { Express that the } \\
\text { benefits of } \\
\text { cessation exceed } \\
\text { the disadvantages } \\
\text { of quitting } \\
\text { Recognize that the } \\
\text { negative } \\
\text { consequtuences of } \\
\text { smoking is } \\
\text { personally relevant } \\
\text { Experience social } \\
\text { accept of smoking } \\
\text { cessation }\end{array}$ & \begin{tabular}{|l|} 
Express \\
confidence \\
regarding ability to \\
quit smoking \\
\end{tabular} & & $\begin{array}{l}\text { Support the person } \\
\text { who wish to stop } \\
\text { smoking (give } \\
\text { positive feedback) } \\
\text { or } \\
\text { Accept that the } \\
\text { person wishes to } \\
\text { stop (does not give } \\
\text { negative feedback) }\end{array}$ \\
\hline $\begin{array}{l}\text { Commit to the quit } \\
\text { attempt }\end{array}$ & $\begin{array}{l}\text { Explain that that it } \\
\text { requires energy to } \\
\text { change behaviour. }\end{array}$ & $\begin{array}{l}\text { Experience that } \\
\text { smoking cessation } \\
\text { is importint and } \\
\text { demands a special } \\
\text { effort. }\end{array}$ & & & \\
\hline $\begin{array}{l}\text { Identify difficult } \\
\text { situations/determin } \\
\text { e smoking } \\
\text { ftnction* }\end{array}$ & $\begin{array}{l}\text { Identify situations } \\
\text { where smoking is } \\
\text { used to cope with } \\
\text { e.g. psychological } \\
\text { problems, sacial } \\
\text { (indirect) pressure } \\
\text { or other sinations } \\
\text { cigarette crivings }\end{array}$ & & & $\begin{array}{l}\text { Demonstrate the } \\
\text { skills to monitor } \\
\text { own dependency }\end{array}$ & \\
\hline $\begin{array}{l}\text { Make coping } \\
\text { plans* }\end{array}$ & $\begin{array}{l}\text { Explain that there } \\
\text { is different types } \\
\text { of coping } \\
\text { strategies and that } \\
\text { the strategies can } \\
\text { be conibined, and } \\
\text { used differently } \\
\text { dependent of the } \\
\text { actual situation }\end{array}$ & \begin{tabular}{|l|} 
Experience that it \\
is important to \\
have a plan for \\
difficult situations \\
Realize that \\
smoking cessation \\
implies certain \\
coping skills \\
Experience that \\
social relations is \\
important in order \\
to successfully quit \\
smoking
\end{tabular} & $\begin{array}{l}\text { Are confident in } \\
\text { own ability to } \\
\text { make appropriate } \\
\text { coping plans }\end{array}$ & $\begin{array}{l}\text { Show the ability to } \\
\text { make a coping } \\
\text { plan for situations } \\
\text { with physiological, } \\
\text { social, } \\
\text { psychological and } \\
\text { others types of } \\
\text { cravings }\end{array}$ & $\begin{array}{l}\text { Agree to support } \\
\text { the quilter }\end{array}$ \\
\hline Quit smoking & $\begin{array}{l}\text { State that it is } \\
\text { better to stop now } \\
\text { than later }\end{array}$ & $\begin{array}{l}\text { Have an intention } \\
\text { to become smoke- } \\
\text { free }\end{array}$ & $\begin{array}{l}\text { Feel confident they } \\
\text { can quit }\end{array}$ & $\begin{array}{l}\text { Can lay down a } \\
\text { quit date }\end{array}$ & $\begin{array}{l}\text { Support the new } \\
\text { behaviour }\end{array}$ \\
\hline $\begin{array}{l}\text { Perform coping } \\
\text { plans }\end{array}$ & $\begin{array}{l}\text { Describe } \\
\text { alternative lines of } \\
\text { action in difficult } \\
\text { situations }\end{array}$ & $\begin{array}{l}\text { Experience accept } \\
\text { of alternative lines } \\
\text { of action }\end{array}$ & $\begin{array}{l}\text { Feel confident they } \\
\text { can ask social } \\
\text { relations about } \\
\text { support } \\
\text { Are confident that } \\
\text { it is possible to } \\
\text { perform the } \\
\text { alternative lines of } \\
\text { action in real life } \\
\text { circumstances }\end{array}$ & $\begin{array}{l}\text { Have skills to } \\
\text { communicate the } \\
\text { wish for support } \\
\text { Have skills to } \\
\text { perform alternative } \\
\text { lines of action in } \\
\text { different } \\
\text { situations with } \\
\text { craving }\end{array}$ & $\begin{array}{l}\text { Accept the new } \\
\text { behaviour }\end{array}$ \\
\hline $\begin{array}{l}\text { Evaluate and } \\
\text { adjust strategies }\end{array}$ & $\begin{array}{l}\text { Srate that cessation } \\
\text { is an ongoing } \\
\text { process that }\end{array}$ & & $\begin{array}{l}\text { Are confident they } \\
\text { are able to change } \\
\text { plans }\end{array}$ & $\begin{array}{l}\text { Can monitor the } \\
\text { efficacy of the } \\
\text { coping strategies }\end{array}$ & \\
\hline
\end{tabular}




\subsection{IM step 3: Theoretical Methods and Practical Strategies \\ Method}

In the third IM step change objectives were linked to practical strategies derived from theoretical methods for behavior change. A method is a general theorybased technique to accomplish changes in behavioural determinants; a practical strategy is the specific application of a method, in such a way that it fits the target group and the intervention context.

\section{Results}

Because of the strong focus in our matrix on motivation, self-efficacy, coping and skills training, we selected Self-Regulation Theory (SRT) (95), the TransTheoretical Model (TTM) (83) and Social Cognitive Theory (SCT) (85) as the theoretical backbone of the intervention. Both SRT and TTM state that people go through several stages ot phases to reach their health goals. This fundamental view not only guided the delineation of performance objectives, but also the identification of potentially useful intervention methods: Consciousness raising (TTM), Dramatic relief (TTM) and Decisional balance (TTM), Modelling (SCT), Guided practice (SCT), Self-monitoring (SRT) and Coping planning (SRT).

We selected 'biofeedback', 'Motivational Interviewing' (MI) and 'behavioural joutnalism' as the main intervention strategics. 'The aim of biofeedback is to enhance personal relevance by providing feedback on individual health conditions (97). This is relevant when people have difficulties in linking the behaviour and health consequences, and if the target group is not aware of the risk of the behaviour. Motivational Interviewing is a client-centred counselling style that supports clients exploting and resolving theit ambivalence about behaviour change (98). In MI four core principles guide the counselling: 1) Expressing empathy (i.e., non-judgemental listening, acceptance and recognition of the clients needs); 2) Developing discrepancy (i.e, highlight the difference between cutrent behaviour: and clients goals); 3) Rolling with tesistance (i.e., avoid arguing for change); and, 4) Enhancing self-efficacy (i.e, by teducing barticts of change and developing skills to overcome problems). In behavioutal journalisin (85) real-life role models serve as the sender of the health messages ensuring that messages are compatible with the noms, perceptions and language of the target population.

When translating methods into strategies it is crucinl to acknowledge that a method may be only effective within certain parameters ot conditions. For instance, behavioural joutnalism is based on modelling, and the parameters for modelling are that the audience can identify with the model, that the model is tewatded for the desired behaviour, that the andience posseses the self-efficacy needed for the desired behaviour, and that the model is a coping model tather than a mastery model (99). This implies that the real-life model stories have to be very carefully selected to meet these parameters. 


\subsection{IM step 4: Programme Development Method}

In IM Phase 4 the actual intervention was designed, produced and piloted. First, we collected most of all existing Danish intervention materials addressing adolescent smoking cessation. Second, a group of five experts and practitioners evaluated if the materials covered one or more of the specified change objectives, and if strategies met the theoretical considerations for use. In case existing materials did not meet these requirements, new materials were produced in order to cover all necessary change objectives.

In the production step of IM dummy versions of the new materials were piloted among 10 adolescent smokers, and revised according to the feedback given. In addition, we secured that the intervention format took into account the factors essential for recruitment and implementation. We designed an intervention that did not require registration beforehand, with easy access, that provided a motivational incentives and that was based on a non-pattonizing approach. In adition, we made a line of support materials awailable in order to be able to tailor the intervention to individual needs and preferences.

\section{Results}

The final intervention included a 'cessation stand' with two counselors offering $\mathrm{CO}$ measurements, proactive non-confronting short counseling based on Motivational Interviewing, and a range of supportive materials, such as self-help guides, postcards, a small competition and referral to an internet/SMS/emailcessation support system. The counseling followed a three step sequence where smokers initially were $\mathrm{CO}$ measured and (dependent of their attitude towards quitting) they were interviewed about their smoking status and history, motivation for quitting, and cessation strategies. In the last step they were referred to additional help (a smoking cessation web-page or/and a cessation guide) and were asked whether they were interested in 'challenging' their smoking. The purpose of the smoking 'challenge' was to give the smokers an opportunity for making a small cessation experience (for instance, not to smoke in the following break); challenges were defined together with the individual adolescent. The events were organized in a centtal place at the school (typically in the cantina) from $10.00 \mathrm{am}$ to $13.00 \mathrm{pm}$ and were run one day a week four weeks in a row.

In addition to the written intervention materials for the adolescents, we developed a manual and a training course for counselors. The manual focused on the core principles of Motivational Interviewing, the adolescent smoking cessation process, the concept of short counseling, and practical information on how to set up a smoking cessation event and how to use the materials as part of the intervention. These topics were also covered in a counseling training including role-playing, demonstrations and supervision.

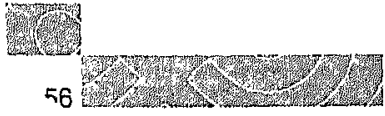




\subsection{IM step: Development of implementation plan \\ Metbod}

The fifth step in IM concerns planning for implementation. In addition to anticipating program implementation from the start of program planning, IM invites interventionists to plan a strategy for the widespread implementation of their program. IM invites interventionists to set up a broad planning group, as well as a linkage group bridging the gap between research and development and program implementation. In addition to anticipating program implementation from the start of program planning, IM invites interventionists to develop a theory- and evidence-based program to facilitate the dissemination of their health promoting program.

\section{Results}

A central-local strategy was developed in order to define responsibilities for all involved partners. The central level were defined as the Danish Cancer Society and the local level as coordinators being responsible for smoking prevention in the counties. A scheme with peformance objectives for the co-ordinaters was made indicating which actions they had to perform in order to secure implementation, These were: Decide to participate in the project, contact relevant schools, enroll schools in the project, identify a contact person at each school, identify relevant student groups, tecruit counsellors, organise special training for the counsellors, and contact schools for planning program execution. The DCS had the overall responsibility for program management and was responsible for monitoring progress in the implementation plan for the co-ordinaters, for developing a web-page with background information relevant for counsellors, for organising a three day course in acklescent smoking cessation counselling and for providing materials with easy access and low cost. In addition, the DCS was responsible for organising annual meetings with all co-ordinaters.

\subsection{IM step 6: Preparing for Process- and Effect Evaluation}

\section{Method}

In step 6 we wrote an evaluation plan with formative and effect evaluation measures based on the objectives identified in the program development process.

\section{Results}

We designed a randomised contrulled trial with 11 intervention and 11 control schools with a measurement of baseline, short-term and long-term effects. On the basis of the previous IM steps we selected the following behavioural variables for the effect evaluation: Smoking, smoking cessation, quitting attempt, change in smoking consumption, and participation in cessation support (other than the intervention). In addition, we choose the following variables focusing on change objectives and determinants: Motivation/decisional balance, awateness of cessation support options, perception of personal health relevance, experience of 
Events for Adolescent Smoking Cessation

social support, self-efficacy expectations and perception of quitting methods. The process evaluation was designed to give us an opportunity for estimating reach and use of the intervention, and allow us to draw a profile of the users of the intervention. The results of this study are reported elsewhere. 


\section{Discussion and conclusion}

\subsection{Discussion}

In this paper we have used the methodology of Intervention Mapping to develop an adolescent smoking cessation intervention with a focus on implementation and recruitment. The main results of the development process are the findings of each of the six IM steps: 1) the identification of personal and external determinants related to adolescent smoking cessation and the identification of implementation and recruitment barriers in both the schools and among the tatget group, 2) the identification of performance objectives, determinants and change objectives for smoking cessation 3) the identification of appropriate methods and strategies, 4) the actual intervention development 5) the implementation plan, and 6) the evaluation plan for both process and effect evaluation. Further, the mapping process revealed that there is a lack of knowledge regarding the importance of environmental factors, such as smoking policies.

Basically, we used two strategies to secure widespread implementation: 1) Involvement of local agents responsible for program diffusion from the start of the intervention secured that they would perceive ownership and commitment towards the intervention, and 2) Focussing on designing the intervention in a format that would appeal to a latge group of adolescent smokers and that can be easily implemented in a school setting.

Nlthough the planning process was guided by IM, not all IM tasks wete completed like sugrgested by the protocol. lirst, time and funding testrictions made it impossible to perform a study on determinants of smoking cessation in a Danish adolescent sample, and no studies have ever been conducted with this regard in Denmark. Therefore, the assumptions on determinants that formed the basis of intervention development might not have been valid for the adoleseents in our trial. However, since both our pilot study and our qualitative study did not reveal major discrepancies between our findings and those of studies among other Nordic populations, we do not consider this a major problem for the development process. Second, when making estimations of importance and changeability of cognitive and social determinants in step 2 we could not find specific recommendations in the literature regarcling adolescent smoking cessation. Therefore, the selection was made on the basis of general scientific insights in the smoking cessation literature and consensus among program plannets. Finally, one could atgue that we selected the schools as setting for the intervention before the actual development process, and therefore choose not to take into considerations alternative delivery platforms tos soon in the process. The reason for this selection was out experience that the adolescents did not want to participate in smoking cessation interventions if participation was too difficult. We therefore designed the intervention to be delivered in a setting that most Danish adolescent use on 
a daily basis. However, we cannot exclude the possibility that other settings could have been suitable for the intervention also.

One of the experienced difficulties of the development process has been to use IM with collaborating partners, who often find the detailed planning superfluous. Especially partners with a practice background find it difficult to 'dwell' on details in the first steps of the development process. In this process the procedures of IM was of great value in order to keep the intervention development process on the right 'track'.

\subsection{Conclusion}

The IM methodology with a clear link between behavioutal goals, theoretical methods and practical strategies and materials proved to be essential to develop as systematic adolescent smoking cessation intervention with strong focus on implementation and recruitment of adolescent smokers.

\subsection{Practice implications}

High transparency of the decisions taken in the development process with insight into both the overall goals of the intervention, the performance- and change objectives, and the theoretical methods and strategies used in the intervention design is crucial when designing health promoting interventions. This knowledge makes it possible to identify specific weaknesses in the intervention, and, subsequently, to make appropriate improvements. In addition, methodological transparency is crucial in order to gain insight into why some seemingly identical interventions are effective and other not, and when transmitting experiences from one intervention area to another $(74 ; 75)$.

\section{Acknowledgement}

This study was funded by a grant from the Danish Ministry of the Interior and Health. The funding sources had no influence or involvement in the making of this research paper. 


\section{Evaluation}


Events for Adolescent Smoking Cessation 


\section{A cluster randomized controlled trial of an adolescent smoking cessation intervention: Short and long term effects}

Peter Dalum*, Georg Paludan-Müller*, Herman Schaalma**, Gerda Engholm* \& Gerjo Kok**

Submitted for publication

*Department of Cancer Prevention \& Documentation, Danish Cancer Society, Denmark

**Department of Experimental Psychology, Faculty of Psychology, Maastricht University, The Netherlands

Running head: Danish randomized trial of adolescent smoking cessation intervention $20(14$

Keywords: Youth, quitting, adolescence, tobacco, program evaluation

Correspondence should be addressed to:

Peter Dalum, Department of Cancer Prevention \& Documentation, Danish Cancer Society, Strandbldv. 49, DK-2l(0), Copenhagen, Denmark, email: pd@ cancer.dk 


\section{Abstract}

Background: There is a lack of effective smoking cessation interventions which have a high reach among adolescent smokers.

Method: We conducted a randomized controlled trial of an adolescent smoking cessation intervention for students age 15-21 at 22 continuation schools in Denmark. Our one-month follow-up consisted of 514 baseline daily smokers and the 14 month follow-up of 369 daily smokers.

Results: We found positive short term effects regarding smoking cessation (Adjusted analysis OR: 4.50; 95\% CI: 1.20-16.86), self-efficacy $(\mathrm{P}=0.01$.) and intentions to quit ( $\mathrm{P}=0.004)$. However, none of these effects were maintained at oneyear follow up. The intervention was successful in reaching more than half of all daily smokers in the target group with more than $30 \%$ receiving counseling at least once in the intervention period.

Conclusion: We found modest short term effects on smoking cessation, self-effcacy and intentions to quit smoking, but none of these effects were sustained at one-year follow-up. Additional research is needed to develop interventions that can maintain effects.

Practice implications: This trial showed that large group of daily smoking adolescents are interested in participating in a smoking cessation intervention as long as participation is made available in the youth environment and do not require to much difficulty.

Word count: Abstracht: 201; Main text 3.724

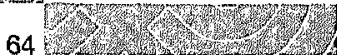




\section{Introduction}

Although the dangers of smoking have been known for half a century, smoking still remains one of the most important challenges to public health (2). Among children and adolescents the effort has been aimed at preventing smoking onset, and only in the recent years has the focus been on smoking cessation interventions for adolescents. A Cochrane review from 2006 found that adolescent smoking cessation (ASC) interventions show promise, but also found important challenges for future research (77).

Prior to intervention development we conducted a pilot study testing a 'conventional' group based five-session smoking cessation program in three different school settings for students aged 16-20 in Denmark (16). The study showed that most schools did not consider smoking cessation a relevant topic for their school curriculum and we concluded that the prerequisites for smoking cessation courses were not present at the schools at that time (2002). We also found that, even though the cessation groups were held during school hours, we were only able to recruit about $5 \%$ of the smokers at the schools. In a qualitative study of the adolescent smoking cessation process, we found that adolescents considered 'willpower' as the most important determinant of smoking cessation and that adolescents expected cessation interventions to be patronizing and regarded support seeking for an internal personal process as excessive (100). These findings were in line with those of McDonald who found that the median recruitment for adult smoking cessation interventions were $2.0 \%$ (17) and Backinget et al. who reported that a researcher might expect between 2 and $10 \%$ recruitment to adolescent smoking cessation interventions (18). If this problem cannot be overcome it is unlikely that ASC programs will have a significant effect on the total smoking proportion among adolescents - even in cases where programs are effective for participants. The challenge for future $\mathrm{ASC}$ programs therefore is to focus not only on program effects, but also on recruitment and implementation of the programs in real life circumstances.

In this trial we tested the effect of an $A S C$ intervention on all daily adolescent smokers at 22 continuation schools for students age 15-21. Our main reseatch questions were whether the intervention was effective in reaching a sizeable amount of the adolescent daily smokers, and whether it was effective in increasing the one-month- and 14 month cessation tates. In addition, we tested whether the intervention had any effects on short and long term cessation attempt and factors thought to influence the cessation process. 


\section{Method}

We conducted a cluster randomized controlled trial (RCT) of an adolescent smoking cessation intervention for students aged 15-21 at 22 continuation schools in Denmatk. The schools were randomised on school level.

\subsection{Procedures}

All 15 counties in Denmatk were contacted and offered participation in the tesearch project. To participate, each county had to enroll two continuation schools for students 15-21 year. In collaboration with the counties we decided to testrict the study to either Commercial- or Social \& Health schools. All schools contacted were informed that participation involved the collection of three rounds of a self-administered questionnaire and that they would receive the intervention in either year one (intervention) or year two (waiting list controls). Eleven counties volunteered to enroll in the project with a total of eighteen Commercial-and four Social \& Health schools.

In order to minimize the effects of geographical differences we secured the tandomization process in such a way that each county comprised both intervention and control schools, and that both the intervention and the control group consisted of nine Commercial and two Social \& Health schools. Due to vatiation in school size and the number of school divisions at the schools, the tandomization yielded 8 divisions of higher-and 9 divisions of lower education in the intervention group, and 6 and 9 divisions of higher and lower education in the control group.

Self- administered questionnaires were collected in week 5/2004 (baseline), week $11 / 2004$ (1. follow-up) and week 11/2005 (2. follow-up) and two cohorts were created by merging respondents from baseline with respondents of 1 st followup (short term follow-up) and tespondents of 2nd follow-up (long term followup) (se figure. 1). All schools collected baseline data, but unfortunately school identification codes were missing from students from one Social and Health school in the control group and could thus not be included. At 2nd follow-up one intervention school lost the collected data and one school from the control group collected data from a wrong school division. In addition, some students had filled in the identification code wrong which caused fewer matching pairs in the cohorts.

The final sample consisted of 514 baseline daily smokers in the short term follow-up group and 369 baseline daily smokers in the long term follow-up group.

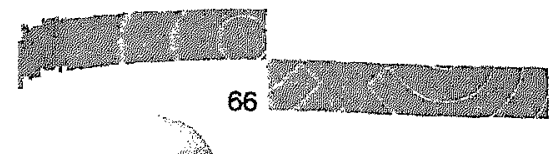


Figure 1: Flow-diagram of the formation of cobort group $A B$ (short term follow-up) and AC (long term followsup).

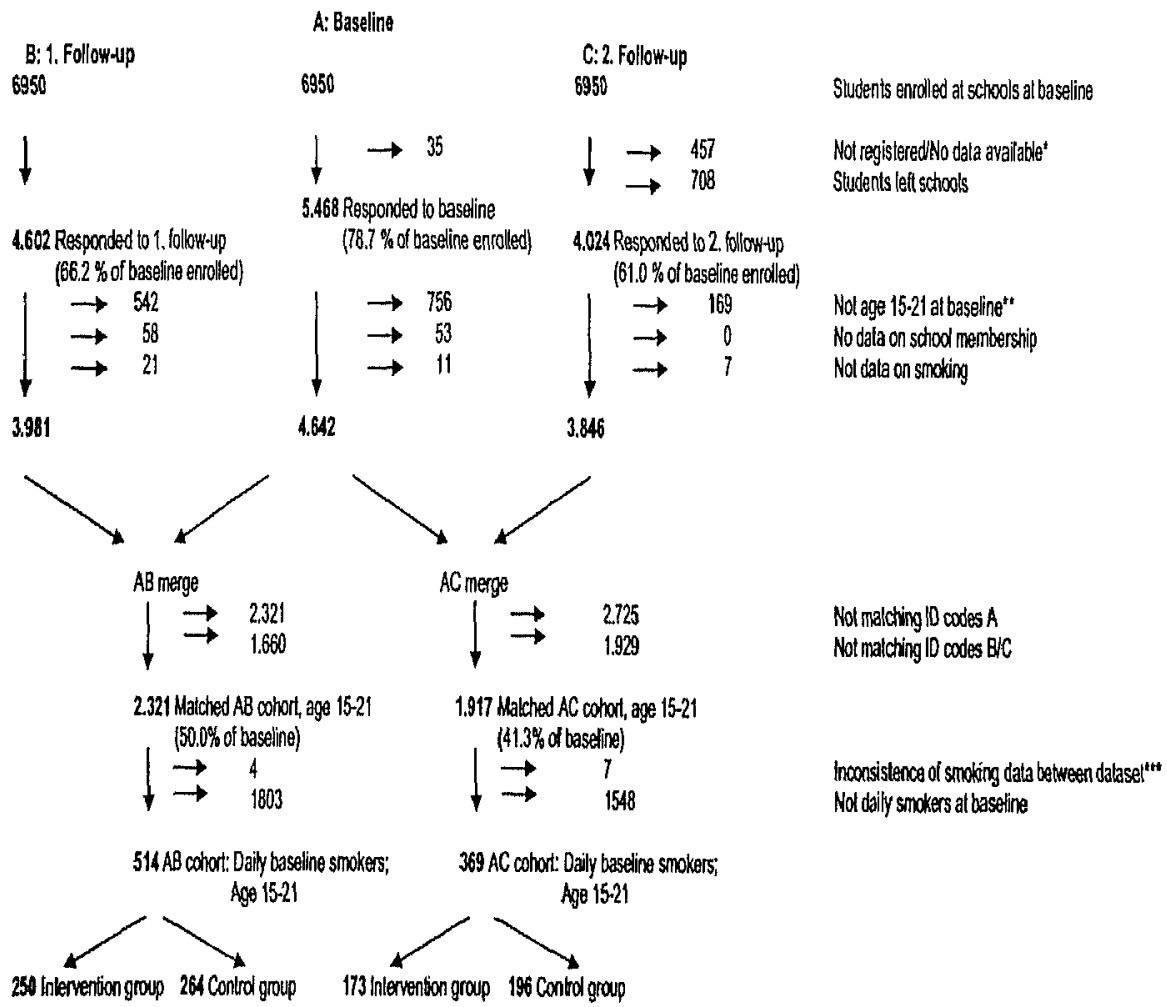

"At baseline data from one school was nod rejistered. At 2 follow up tho schoods did nol collect data.

"In case of lack of baseline data we used data from 1. and 2. follow-up lo estimale baseline age

"'Eg: Reporting being dolly smoker al baseline and newer-smoker al followlp.

\subsection{The intervention}

The intervention development was based on the methodology of Intervention Mapping (IM) (7.3) and a thorough development description is provided elsewhere (Dalum et al. in production). The IM methodology revealed that successful quitting was related to a line of performances or sub-behaviors, which, in turn, was found to be related to specific change- and learning objectives (see table 1). The performance and change objectives functioned as the basis the intervention development ptocess and guided the formation of evaluation measures. 
Table 1: Danish randomized trial of adolescent smoking cessation intervention 2004.

Performance objectives and examples of related change and learning objectives

\begin{tabular}{|c|c|}
\hline $\begin{array}{l}\text { Pefformance } \\
\text { objectives }\end{array}$ & Change and learning objectives (selected examples) \\
\hline $\begin{array}{l}\text { Decide to quit } \\
\text { smoking }\end{array}$ & $\begin{array}{l}\text { Being able to mention reasons for quitting smoking } \\
\text { Experience that the benefits of cessation exceed the disadvantages of } \\
\text { quitting } \\
\text { Experience parsonal relevance of the negative consequences of smoking }\end{array}$ \\
\hline $\begin{array}{l}\text { Commit to the quit } \\
\text { attempt }\end{array}$ & $\begin{array}{l}\text { Experience that smoking cessation is important and demands a special } \\
\text { effort. }\end{array}$ \\
\hline $\begin{array}{l}\text { Identify difficult } \\
\text { siluations }\end{array}$ & Have the skills to monitor own dependency \\
\hline Make coping plans & $\begin{array}{l}\text { Be able to make a coping plan for situations with physiological, social, } \\
\text { psychological and others types of cravings } \\
\text { Knowing that different types of coping strategies exist and that strategies can } \\
\text { be combined, and used different depending on the specific situation }\end{array}$ \\
\hline Quit smoking & $\begin{array}{l}\text { Knowing that it is better to stop now than later } \\
\text { Have an intention to become smoke-free } \\
\text { Feel confident to be able quit } \\
\text { Can set a quit date }\end{array}$ \\
\hline Perform coping plans & $\begin{array}{l}\text { Believe that it is possible to perform coping responses in real life } \\
\text { circumstances } \\
\text { Have skills to perform coping responses in different situations with craving }\end{array}$ \\
\hline $\begin{array}{l}\text { Evaluate and adjust } \\
\text { strategies }\end{array}$ & $\begin{array}{l}\text { Know that cessation is an ongoing process that requires a continuous effort } \\
\text { Know where to seek help in difficult situations } \\
\text { Can monitor the effect of the coping strategies } \\
\text { Can change or replace ineffective strategies }\end{array}$ \\
\hline Maintain cessation & $\begin{array}{l}\text { Know that some conditions change as part of the quitting process } \\
\text { Gives attention to both positive and negative changes of the cessation } \\
\text { process } \\
\text { Can registate the changes of the cessation process } \\
\text { Can determine strategies to cope with negative side effects. }\end{array}$ \\
\hline
\end{tabular}

Theoretically the intervention was based on Self-Regulation theory (95), the Trans Theoretical Model (83) and Social Cognitive theory (85). From these theories we selected guided practice, modelling, self-monitoring, coping planning, consciousness taising, dramatic relief and decisional balance as methods suitable for adolescent smoking cessation interventions.

In practice, the intervention was based on open events where all smokers and ex-smokers were offered the following: 1) Carbon monoxide measurement; 2) a personal and short counselling based on 'Motivational Interviewing' focused on

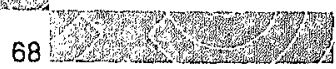


motivation for quitting, management of cigarette craving, problem solving and development of cessation skills; 3) self-help materials with a combination of quit-guides and various postcards/materials; 4) referral to a smoking cessation program using Internet, SMS and E-mail, and 5) referral to telephone counseling. The events took place centrally at the school (typically in the cantina) in the time period 10.00 to 13.00 and were offered once a week in four sequential weeks. The counseling was carried out by experienced nurses who had attended a minimum of three day smoking cessation counseling course and in addition were trained directly for this project.

The intervention took place in the weeks 6-10 (2004) at the intervention schools and in the weeks 13-16 (2005) at the control schools after the 2nd followup.

\subsection{Measurements:}

\section{Smoking}

Assessment of smoking status was based on self-teports. Participants were asked whether they smoked daily, weekly, once a month, or were non-smokers. In addition, we asked for smoking consumption, years of smoking, and previous smoking.

\section{Cessation}

Short- and long term cuitters were defined as students who were daily smokers at baseline and 1) had quit smoking within the last 30 days at 1st follow-up; 2) had been smoke-free for at lenst the last 30 days at 2 nd follow-up.

\section{Cessation attempt}

Short- and long term cessation attempts were defined among daily smokers at baseline as those who had either quit smoking or had tried to cuit smoking within 1) the last 30 days at 1 st follow-up; 2) the last 14 month at 2 nd follow-up.

\section{Intentiont to quit}

According to Trans Theoretical Mockel, smokers and ex-smokers can be subdivided into: pre-contemplation (no actual plans for yuitting), contemplation (plans for quitting within next six month), preparation plans for quitting within next month) or action (quitted smoking within six month. By comparing the baseline status to the status at follow-up we eletermined whether a negative stage progression (moving to a stage closer to the precontemplation stage), a pessitive stage progression (moving to a stage closer to the action stage) or no) progression had been made.

\section{Self-efticacy}

Pntricipants were asked to indicate on al five point Likert scale from 'definitely' to 'definitely not" if they thought they could refrain from smoking in 12 typical 
smoking triggering situations (E.g. "Do you think tbat you can refrain from smoking if you spend time mith people who smoke"). We created a scale from the 12 items (Cronbachs alpha $=0.87$, and calculated the sum of change for all 12 items from baseline to 1st follow-up.

Health beliefs, knowledge and attitudes towards cessation Participants were asked to indicate on a five point Likert scale from 'agreed' to 'disagreed' with statements regarding 1) bealth beliefs (seven items) e.g. "Smoking is damaging to health", 2) knowledge of cessation support (one item) "I know where young people can get help to quit smoking", 3) cessation preparation strategies (five items) e.g. "If I were to quit smoking, I would quit from one day to the next", 4) individual cessation strategies (seven items) e.g. "If I were to quit smoking, I would eat candy, fruit or something else when I felt the urge to smoke" and 5) strategies for obtaining social support (five items) e.g. "If I were to quit smoking, I would tell my closest friends that I was quitting". We tested for correlation between the items tegarding health beliefs. However the Cronbach alpha was to low to justify scale construction. Therefore we analyzed the items individually.

\section{Decisional balance}

We measured decisional balance by asking the students to indicate whether or not they agreed to twenty (ten positive and ten negative) statements about smoking (e.g. [positive statement] "Smoking is good when you are bored"; [negative statement] "My parents do not like that I smoke"). If students agreed with a positive statement they got +1 and if they agteed with a negative statement they got -1 . In cases with no indication they got 0 . We calculated the total decisional balance by summing up all statements.

\section{Communication about smoking}

To test whether the intervention did put smoking "on the agenda" of youth, we asked whether they had talked: "more than usual", "as ustul", or "less than uswal" about smoking with their friends within the last two weeks.

\section{Social influence}

To describe social influence we asked for: "Parents snzoking", "sibling smoking", "girtfriend/ boyfriend smoking", "best friends' smoking", "perceived number of smokers among friends",

\section{Background factors}

In addition we asked for the following background factors: "school type", "sex", "etbricitity" and "age".

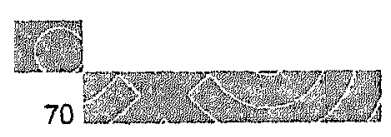




\section{Reach of intervention}

At 1 st follow-up we asked whether the students had received any type of information material concerning smoking at the school and whether they had received any type of counseling/CO measurements (from none/one/two/three/four/ more than four times) within the last five weeks.

\section{Process evaluation}

From one representative of each school we collected questionnaires with questions about the numbers of counselors, numbers of carbon monoxide measurements made at each event, estimation of time disposal in the counseling and general comments about the event. In addition we contacted one representative of each school on phone and made a short semi-qualitative interview about their experiences with holding the event. Focus in the interview was whether they felt they had had the necessary training for the project, and how they used the materials as part of their counseling at the events.

\subsection{Statistical analysis}

Analyses were performed as 'intention to treat' and therefore all baseline smokers were included at both intervention and control schools when determining intervention effects. Significance level $\alpha=.05$ was used. Since data were collected from schools we evaluated the effect of clusters by school using multilevel analysis. Due to low number of included stmokers it was only possible to estimate interdependency with one factor at a time, but we found no indication of 'school interdependency' in the data. Therefore ordinary logistic regression was used in analysis of results regarding 'snoking cessation' and 'quit attempts'. Statistical software for the analysis was $S \Lambda S$ version 9.1 . 


\section{Results}

\section{Sample characteristics}

Table 2 shows the baseline data of all participants at the three questionnaires, and table 3 shows the baseline data from the two follow-up groups.

Table 2: Danish randomized trial of adolescent smoking cessation intervention 2004. Data from baseline, 1. follows-up after six weeks and 2. follow-up after 14 month

\begin{tabular}{|c|c|c|c|}
\hline & $\begin{array}{l}\text { Baseline } \\
(N=4.642)\end{array}$ & $\begin{array}{l}\text { Short-term, follow-up } \\
(\mathrm{N}=3.981)\end{array}$ & $\begin{array}{l}\text { Long-term. follow-up } \\
\langle\mathrm{N}=3.846\rangle\end{array}$ \\
\hline \multicolumn{4}{|l|}{ Smoking status: } \\
\hline - Daily smokers & $24.7 \%$ & $24.1 \%$ & $22.7 \%$ \\
\hline - Weekly smokers & $4.7 \%$ & $4.6 \%$ & $4.7 \%$ \\
\hline - Occasionally smokers & $8.1 \%$ & $7.3 \%$ & $7.6 \%$ \\
\hline - Non smokers & $62.4 \%$ & $64.0 \%$ & $65.2 \%$ \\
\hline Sex: boys & $39.5 \%$ & $39.4 \%$ & $39.5 \%$ \\
\hline Mean age & $17.5 \mathrm{yrs}$ & $17.6 \mathrm{yrs}$ & $18.5 \mathrm{yrs}$ \\
\hline Education: Higher & $60.5 \%$ & Not measured & Not measured \\
\hline Eltnichty: Danish & $84.2 \%$ & Not measured & Not measured \\
\hline In intervention group & $51.6 \%$ & $52.9 \%$ & $43.4 \%$ \\
\hline
\end{tabular}

To check whether our tandomization was successful or we had to control for possible confounding factors, we checked whether there was an equal distribution between the intervention and the control group regatding all relevant factots measured (see table 3). In the short term follow-up we found significant differences regarding the variables educational level, ethnicity, self-efficacy and girl/boy-friend smoking. In the long term follow-up we found only significant differences regarding educational level. These variables were included in the adjusted analyses. 
Table 3: Danish randomized trial of adolescent smoking cessation intervention 2004. Baseline data for the lony- and short term cohorts of baseline smokers age 15-21.

\begin{tabular}{|c|c|c|c|c|c|c|}
\hline Daily smokers at baseline & $\begin{array}{l}\text { AB: Short term } \\
(N=514)\end{array}$ & follow-up & $\begin{array}{l}\text { Tesl for } \\
\text { homo- } \\
\text { geneily }\end{array}$ & $\begin{array}{l}\text { AC: Long term } \\
\langle N=369)\end{array}$ & follow-up & $\begin{array}{l}\text { Test for } \\
\text { homo- } \\
\text { geneily. }\end{array}$ \\
\hline & $\begin{array}{l}\text { Intervention } \\
(N=250)\end{array}$ & $\begin{array}{l}\text { Conirol } \\
(\mathrm{N}=264)\end{array}$ & $P$ & $\begin{array}{l}\text { Intervention } \\
(N=173)\end{array}$ & $\begin{array}{l}\text { Control } \\
(N=196)\end{array}$ & $p$ \\
\hline Age (Mean yrs) & 17.7 & 17.7 & .63 & 17.6 & 17.6 & .66 \\
\hline Mean cig/day & 12.0 & 12.2 & .67 & 12.1 & 11.4 & .29 \\
\hline $\begin{array}{l}\text { Mean years of smoking } \\
\text { (yrs) }\end{array}$ & 3.9 & 4.2 & .07 & 3.8 & 4.1 & .11 \\
\hline Ethnicily: Danish & $88.8 \%$ & $81.6 \%$ & .02 & $90.6 \%$ & $85.3 \%$ & .13 \\
\hline Sex: Boy & $31.3 \%$ & $28.2 \%$ & .44 & $29.2 \%$ & $29.5 \%$ & .95 \\
\hline Education: higher & $63.0 \%$ & $33.0 \%$ & $<.0001$ & $76.0 \%$ & $44.1 \%$ & $<.0001$ \\
\hline Parent(s) smaking & $67.2 \%$ & $65.3 \%$ & .64 & $65.5 \%$ & $60.8 \%$ & .36 \\
\hline Sibling(s) smoking & $50.0 \%$ & $45.5 \%$ & .32 & $50.6 \%$ & $44.4 \%$ & .25 \\
\hline Girlboyfriend smoking & $36.7 \%$ & $45.7 \%$ & .04 & $36.3 \%$ & $44.9 \%$ & .10 \\
\hline Best thiend smoking & $90.3 \%$ & $92.4 \%$ & .41 & $87.9 \%$ & $91.3 \%$ & .27 \\
\hline $\begin{array}{l}\text { Perceived proportion of } \\
\text { friends smoking: }\end{array}$ & & & .27 & & & .20 \\
\hline Most non smokers & $6.1 \%$ & $8.0 \%$ & & $8.2 \%$ & $8.9 \%$ & \\
\hline -Filfylifity & $31.3 \%$ & $25.3 \%$ & & $34.7 \%$ & $26.0 \%$ & \\
\hline Mosi smokers & $62.6 \%$ & $66.7 \%$ & & $57.1 \%$ & $65.1 \%$ & \\
\hline $\begin{array}{l}\text { Self efficacy regarding } \\
\text { cessation (1-60) (mean) } \\
\text { (60) Low SE) }\end{array}$ & 36.8 & 38.8 & .04 & 37.0 & 38.1 & .30 \\
\hline Intentions to quit smaking & & & .16 & & & .36 \\
\hline -Within next month & $12.6 \%$ & $8.4 \%$ & & $12.8 \%$ & $8.3 \%$ & \\
\hline - Within next 1.6 months & $12.6 \%$ & $16.9 \%$ & & $16.3 \%$ & $18.1 \%$ & \\
\hline $\begin{array}{l}\text {-No intentions/some- } \\
\text { times in future }\end{array}$ & $74.9 \%$ & $74.7 \%$ & & $70.9 \%$ & $73.6 \%$ & \\
\hline Decisional balance: & & & .39 & & & .95 \\
\hline -Most Pros & $19.6 \%$ & $22.7 \%$ & & $19.7 \%$ & $19.9 \%$ & \\
\hline -Most Cons & $80.4 \%$ & $77.3 \%$ & & $80.4 \%$ & $80.1 \%$ & \\
\hline
\end{tabular}

Lost from follows up

We checked whether there was a difference between those who only responded to baseline (drop-outs) with those who also responded oo the 1 st follow up, and found significant differences regarding sex, ethnicity, educational level and girl/ boyfriend smoking. However, except regarding educational level, these differences were similar for both the intervention and the control group. 


\section{Smoking cessation}

The main shott and long term effects regarding cessation can be found in table 4 and 5 . After the 1 st follow up 12 adolescents $(4.8 \%)$ in the intervention group versus 4 adolescents $(1.5 \%)$ in the control group teported having quitted smoking, and $45(18.6 \%)$ in intervention versus $34(13.4 \%)$ in the control group had tried to make a quit attempt. After one year the number of quitters was 11 $(7.5 \%)$ at the intervention and $12(7.1 \%)$ at the control schools and $83(49.4 \%)$ in intervention versus $98(51.9 \%)$ in the control group had tried to make a quit attempt.

Table 4: Damish randomized trial of adolescent smoking cessation intervention 2004. Short term OR for cessation and for making a cessation attempt for daiby smokers at the intervention scbools compared to control schools.

\begin{tabular}{lrrrrrr}
\hline $\mathrm{N}=514$ & Crude & $(95 \% \mathrm{Cl})$ & & Adjusted & $(95 \% \mathrm{Cl})$ & \\
& OR & & $P$ & $\mathrm{OR}^{*}$ & & $P$ \\
\hline Cessation & 3.27 & $1.04 ; 10.30$ & 0.05 & 4.50 & $1.20 ; 16.86$ & 0.03 \\
Cessation & 1.49 & $0.91 ; 2.41$ & 0.11 & 1.52 & $0.90 ; 2.58$ & 0.12 \\
attempt & & & & & & \\
\hline
\end{tabular}

*Adjusted for baseline education level, ethnicity self-efficacy and boy/girl-friend smoking

Table 5: Danish randomized trial of adolescent smoking cessation intervention 2004. L.ong term OR for cessation and for making a cessation attempt for daily smokers at the intervention schools compared to control schools.

\begin{tabular}{lrrrrrr}
\hline $\mathrm{N}=369$ & Crude & $(95 \% \mathrm{Cl})$ & & Adjusted & $(95 \% \mathrm{Cl})$ & \\
& $\mathrm{OR}$ & & $\mathrm{P}$ & $\mathrm{OR}^{*}$ & & $P$ \\
\hline Cessation & 1.07 & $0.46 ; 2.49$ & 0.88 & 0.75 & $0.31 ; 1.82$ & 0.53 \\
Cessation & 0.91 & $0.60 ; 1.37$ & 0.61 & 0.97 & $0.62 ; 1.50$ & 0.89 \\
attempt & & & & & & \\
\hline
\end{tabular}

*Adjusted for baseline education level

\section{Analysis of sensitivity}

In order to evaluate whether our short term results on cessation and cessation attempts was due to chance only, we included those who only responded to our 1 st follow-up in the crude analysis. This was possible since we had a direct question in the follow-up questionnaire on smoking cessation. By including this group we gained power ( $N=998$ participants compared to previous $N=512$ ) but at the same time lost the possibility of making adjusted analyses. Results showed that 
the OR for quitting in the intervention versus the control group was $2.02(95 \%$ CI:1.02-4.01) and regarding making a cessation attempt OR was 1.64 (95\% CI: $0.943-2.855)$.

\section{Intention to quit}

At short term follow-up the OR of making a positive stage progression in the intervention group compared to the control group was 2.18 (95\% CI: $1.28 ; 3.71)$ and for a negative stage progression OR was 1.07 (95\% CI: 0.59; 1.92) indicating an ovetall positive short- term effect on stage progression at the intervention schools.

\section{Self-efficacy}

We found a small but significant short term effect of change in self-efficacy between the intervention and control group. Net change in self-efficacy from baseline to first follow-up was 1.88 in the intervention group ( $\mathrm{SD}=9.02)$ and 0.63 in the control group $(\mathrm{SD}=8.96), \mathrm{P}=.01$.

Health beliefs, knowledge and attitudes tonzards cessation

We found only very small changes in health beliefs, knowledge of cessation support and attitudes towards cessation from at short term follow-up and none of these were significant (data not shown).

\section{Decisional batance}

The intervention had no short term effect on decisional balance: Net change in decisional balance from baseline to first follow up was 0.16 in the control group $(\mathrm{SD}=2.19)$ and $(0.25(\mathrm{SD}=2.06)$ in the intervention group, $\mathrm{P}=0.65$.

\section{Communication about smoking}

$16.9 \%$ of the smoking participants at the intervention schools and $12.6 \%$ of the smoking participants at the controls reported having talked more about smoking among with their friends at school in the last 14 days prior to 1 st follow-up, and respectively $6.2 \%$ and $7.5 \%$ reported having talked less. However, the differences were not significant.

\section{Reach of interyention}

Table 6 shows the reach of the intervention among baseline smokers in the shore term follow-up group. An average of $30.2 \%$ of all daily smokers at baseline had at least one contact with a smoking cessation counselor, and $57.4 \% 11$ received either counseling or/and written material. When comparing the group whos received counseling at least once with the non-participants we found that only educational level predicted participation. Students in lower education were more likely to participate than the students in higher education $(P=.(12)$. 
Table 6: Danish randomized trial of adolescent smoking cessation intervention 2004. Reach of the intervention among daily smokers at the intervention schools.

\begin{tabular}{|c|c|c|c|}
\hline & $\begin{aligned} \text { Total } & \\
& N=238(\%)\end{aligned}$ & $\begin{array}{r}\text { Lower education } \\
n=86(\%)\end{array}$ & $\begin{array}{r}\text { Higher education } \\
n=148(\%)\end{array}$ \\
\hline $\begin{array}{l}\text { Non-participants/No } \\
\text { reach }\end{array}$ & 42.7 & 39.5 & 43.24 \\
\hline $\begin{array}{l}\text { Received only written } \\
\text { material }\end{array}$ & 27.1 & 17.4 & 33.11 \\
\hline $\begin{array}{l}\text { Only one contact to } \\
\text { counselor }\end{array}$ & 19.7 & 31.4 & 13.51 \\
\hline $\begin{array}{l}\text { More than one contact } \\
\text { to counselor }\end{array}$ & 10.5 & 11.6 & 10.14 \\
\hline
\end{tabular}

We found large variation in intervention reach between schools: ranging from $81.8 \%$ of student reporting having received either counseling or/and written material in the best example to $33.4 \%$ in the worst case. We were not able to fully explore this variation on the basis on the data available, but in one school the counselor reported that the school had been closed due to a snow storm at two of the intervention days, and in another school the counselor reported that facilities for delivering the intervention were poor due to the refurbishing of the school cantina.

\section{Process evaluation}

Out process questionnaires and the interviews indicated that the counselots had good expetiences holding the events. They experienced good responses from the students, and recieved positive feedback from both the teachers and the managers at the schools. They reported that they felt qualified for the project, and that the special training and the counselor guide provided sufficient preparation. When holding the event, some occasionally felt pressed on time (in peak hours), but in general they indicated that they had sufficient time for the counseling. One of the exercises in the event was only used occasionally, but in general they reported using all materials. 


\section{Discussion}

\subsection{Discussion}

In this paper we have presented the evaluation of an adolescent smoking cessation intervention aimed at continuation schools in Denmark. We found positive short term effects of the intervention regarding cessation, self-efficacy change and intention change. However, none of these effects were maintained at oneyear follow up. The intervention was successful in reaching more than half of all daily smokers in the target group with more than $30 \%$ receiving counseling at least once in the intervention period. Process evaluations showed a high level of satisfaction with the intervention among the counselors and schools principals, but also tevealed a large vatiation in teach between schools indicating room for improvement in future interventions.

Since others have shown that long term effects of cessation interventions can be achieved $(77 ; 89 ; 101)$ it is questionable whether our intervention design can be recommended in its cutrent form. However, in a wider perspective the positive results on reach of the intervention have some implications for future research and intervention development. Out trial shows that in the best examples it is possible to get in contact with mote than $75^{1 \%}$ of all adolescent smokers at a youth educational institution and that short term effects can be achieved. In the interpretation of these results, it is necessary to take into account that our intervention was based on voluntary participation, that the cessation events were held at relatively latge schools, and that no special effort was made to make students participate. The students patticipated because they either passed by the intervention by chance when visiting the school cantina or because they were encouraged by friends or classmates. Since the schools did not allow students to use school hours for the intervention, participants had to use their breaks or free periods when participating. This indicates, that in spite of the numetous studies indicating that adolescents have wather negative pereeptions towards smoking cessation interventions $(78 ; 82 ; 9)$, there is a strong interest for taking part in interventions as long as participation is made available in the youth envitonment and do not require to much difficulty.

In future research it would be interesting to see if this approach can be combined with other more intensive interventions like group counseling, individual counseling, or intensive Internet support. In addition, out results indicated a large variation in level of implementation at the schools. Future research is needed in order to identify whether the differences in implementation were due to factors like timing of the intervention, lack of communication with intervention schools, facilities at schools, the skills/education/selection of the counselors, or the training course for counselors in the project. 
In this trial we used a cluster-randomized design to test the effects of an $\Lambda$ SC intervention on the whole group of baseline daily smokers. Therefore, we did not have the usual problems seen in non-randomized trials with baseline differences between intervention participants and controls (e.g. differences in motivation / intentions towards quitting). However, this study also had some limitations potentially biasing the results of the study:

The randomization process yielded an unequal distribution of numbers of students in lower and higher education, ethnicity, self-efficacy and boy/girl-friend smoking between the control and intervention schools. However, when controlling for these potential confounders we found no effect of any of the intervention effects.

Multilevel analysis with the factor 'intervention' included in the model did not converge due to small numbers. Therefore it was not possible to adjust for possible school effects in the analysis. However, multilevel analysis of single variables indicated no effects of school level. In addition, the matched design took into account possible effects of geographical and school type differences. Third, since only two school types were enrolled little variation could be expected between schools. We therefore assume that there was only a limited chance that school influences have biased our results.

We had no biochemical validation of self-reports on smoking. Although selfreports have been found reliable in many adolescent smoking studies (102), there is still debate on this issue, especially in cases were self-teports are used in controlled trials (103). Potentially unreliability in self-reports would only be a major problem if there were difference in reliability of self-teports between the intervention and the control group. One way of optimizing self-reporting is to secure strict confidentiality of the responses. Confidentiality procedures were carefully applied in this study.

\subsection{Conclusion}

We evaluated the effect of an easily implemented adolescent smoking cessation intervention. The intervention was successful in reaching more than half of all daily smokers in the target group with more than 30\% receiving counseling at least once in the intervention period. We found modest short term effects on smoking cessation, self-efficacy and intentions to quit smoking, but none of these effects were sustained at one-year follow-up. Additional research is needed to develop interventions that can maintain effects.

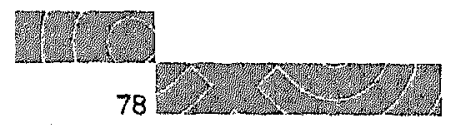




\subsection{Practice implications}

In spite of relatively negative perceptions of formalized smoking cessation interventions a large group of daily smoking adolescents are interested in participating in a smoking cessation intervention as long as participation is made available in the youth environment and do not require to much difficulty.

\section{Acknowledgements}

This study was funded by a grant from the The Health Insurance Foundation of Denmark (Sygekassernes F-lelsefond). The funding sources had no influence or involvement in the making of this research paper. 
Events for Adolescent Smoking Cessation

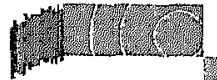

80 䟢 
5 Discussion 
Events for Adolescent Smoking Cessation

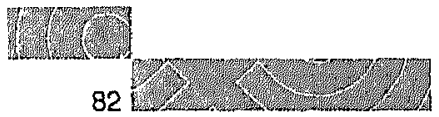


In this thesis we have described the development and evaluation of an evidence based adolescent smoking cessation program. Our introductory work identified a major paradox with regard to adolescent smoking cessation: Although more than $40 \%$ of all smokers reported that they have tried to quit smoking within the last 12 months (23), the majority of adolescents indicates that they would not participate in a smoking cessation intervention $(78 ; 82 ; 90)$ and researchers might expect that only 2 to $10 \%$ of adolescent smokers will participate in their smoking cessation interventions (18). In addition our pilot test showed that it would be difficult to implement smoking cessation interventions in the Danish school setting. Therefore the main questions for this thesis have been: 1) Which are the effective methods and strategies for adolescent smoking cessation? 2) How do we communicate or deliver these in a format that is easily implemented in a Danish school setting and in a way that we recruit a sizeable amount of adolescent smokers?

In order to answer these questions, we conducted a qualitative study focusing on the adolescent smoking cessation process and adolescents view on smoking cessation (see chapter 2). In addition, we searched the literature for determinants of smoking cessation and for effective elements in existing smoking cessation interventions. On this basis we developed an intervention using the methodology of Intervention Mapping (see chapter 3). Finally, we evaluated our intervention with regard to effect on cessation, cessation parameters and recruitment of daily smokers (see chapter 4).

In the following section we will briefly present the main results of each of the three studies and we will discuss their limitations. Thereafter we will discuss the findings with regard to recruitment and intervention content in more detail.

\section{The adolescent smoking cessation process}

The purpose of our qualitative study was to identify strategies and approaches used in the adolescent smoking cessation process and attitudes and beliefs of adolescents towards the process of smoking cessation and smoking cessation interventions. The main finding was that adolescent smoking cessation should be seen as an individual process and that all stages in this process are characterized by a broad variety of quit and maintenance strategies. We could not identify a strategy being superior in explaining the success of quit attempts, but we found that success was related to whether or not the quitter was committed to a learning process in which different strategies were tested, evaluated re-tested, et cetera. In addition the study tevealed that adolescents considered 'willpower' as 
the most important determinant of smoking cessation, that they expected cessation interventions to be patronizing, and that they regarded seeking support for an internal personal process as excessive. The study further revealed that easy access, a motivational incentive, a non-patronizing support, high flexibility and tailoring with strong focus on individual needs and demands was crucial for their willingness to participate in smoking cessation interventions. This suggests that interventionists should take these factors into consideration as part of intervention development.

\section{Intervention development}

In chapter 3 we described the development process of our intervention and how we used Intervention Mapping as planning tool for intervention development. We found that adolescent smoking cessation should be seen as a process influenced by both individual determinants (e.g. knowledge, attitudes, self-efficacy and coping skills) and interpersonal determinants (e.g. friends support), and that quitting was related to the following performance objectives: Decide to quit, decide to make a committed effort to quit, prepare coping plans, quit smoking, identify trigger situations, make/perform coping plans, and evaluate and adjust coping strategies. Further we identified a line of change objectives telated to each of these performance objective : e.g. 1) Young smokers are able to mention reasons for quitting smoking, 2) expetience that the benefits of cessation exceed the disadvantages of quitting, 3) experience personal relevance of the negative consequences of smoking, 4) experience that smoking cessation is important and demands a special effort, 5) have the skills to monitor own dependency, 6) are able to make a coping plan for situations with physiological, social, psychological and others types of cravings, 7) can identify strategies to cope with negative side effects (see the matrix in chapter 3 for all change objectives).

We identified Self-Regulation Theory, the Trans Theoretical Model and Social Cognitive Theory (85) as relevant theories for program development, and from these theories we selected guided practice, modelling, self-monitoring, coping planning, consciousness raising, dramatic telief and decisional balance as methods suitable for adolescent smoking cessation interventions. In the strategic translation of these methods into practical strategies, we selected 'biofeedback', 'Motivational Interviewing' and 'Behavioural Journalism' as the main intervention strategies.

Since the anticipation of implementation and tecruitment of smokers was crucial in the intervention development, in the production phase we ensured that the intervention format took into account the factors that seemed essential for recruitment and implementation. Consequently, we designed an intervention based upon voluntary participation that did not require registration beforehand, that was accessible, that included the provision of motivational incentives and a non-patronizing support. Furthermore, we designed the intervention in such a way that intervention strategies could be tailored to individual needs and demands.

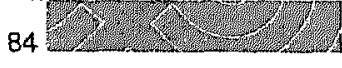


The actual intervention took form as a 'cessation stand' with two counselors offering $\mathrm{CO}$ measurements, a proactive and non-confronting short counseling based on Motivational Interviewing, and a range of supporting materials, such as self-help guides, postcards, a small competition and refertal to an internet/SMS/ email-cessation support system.

During program development it became clear that a platform for information exchange and education of counsellors would be crucial to securing implementation of the intervention. We therefore developed a web-page with background information relevant for counsellors and co-ordinators, and a three day training course in adolescent smoking cessation counselling.

\section{The evaluation situcly}

The purpose of the evaluation was to test the effect of the intervention on all daily adolescent smokers at 22 continuation schools for students age 15-21. The main research questions were whether the intervention was effective in reaching a sizeable amount of the adolescent daily smokers, and whether it was effective in increasing the one-month- and 14 month cessation rates. In addition, we studied whether the intervention had any effects on short and long term cessation attempt rates and factors thought to influence the cessation process.

We found positive short term effects of the intervention regarding cessation, selfefficacy change and intention change. However, none of these effects were maintained at one-year follow up. The intervention was successful in reaching more than half of all daily smokers in the target group with more than $30 \%$ teceiving counseling at least once in the intervention period. Process evaluations showed a high level of satisfaction with the intervention among the counselors and schools principals, but also revealed a large variation in teach between schools indicating toom for improvement in future interventions.

\section{Methodological issues}

\section{Qualitative study}

Practical restrictions made it impossible to perform the qualitative study among students from the schools types intended to participate in the later effect study. Instead, we used a sample from our national smoking cessation competition. This selection criterion enabled us to interview a group of adolescents who initiated their quit attempt on the same date, but it might have biased the study in several ways. First, the interviewees must be considered to be more motivated to quit than the general youth smoking population. Consequently, we might have overlooked quit strategies used by people with low motivation and involvement. Second, the competition might have raised awareness among the interviewees. Consequently, they have been more conscious and reflective about the cessation process than the general population of smoking youth. Third, the cessation 
intervention had some educational elements regarding preparation, motivation and coping that might have led to uniform perspectives regarding the cessation process, and a more positive attitude regarding cessation interventions.

\section{Intervention development}

Although Intervention Mapping proved to be a useful guide for program development, we were unable to fully apply the protocol. Time and funding restrictions made it impossible to perform a study on determinants of smoking cessation in a Danish adolescent sample, and no studies have ever been conducted in this regard in Denmark. Therefore, the assumptions on determinants which formed the basis of intervention development might not have been valid for the adolescents in our trial. However, since we did conduct a pilot study and a qualitative study on Danish youth and since we did not find major discrepancies between our findings and what is seen in countries with a close cultural background to Denmark, we do not consider this a major problem for the development process.

In addition, when making estimations of importance and changeability of cognitive and social determinants in step 2 we could not find specific recommendations in the literature regarding adolescent smoking cessation. Therefore, the selection was made on the basis of general scientific insights in the smoking cessation literature and consensus among program planners.

The selection of change methods and strategies in step 3 was based on a judgement among progtam planners, and we cannot exclude the possibility that other methods could potentially be more effective than the ones we choose. Finally, one could argue that we selected the schools as setting for the intervention before the start of the actual development process, and we therefore neglected alternative delivery platforms. However, we had good reasons for our early decision to focus on schools. Since it was our experience that adolescents would not be willing to participate in smoking cessation interventions if these were too difficult to participate in, we decided to design an intervention matching a setting that most Danish adolescent use on a daily basis. However we cannot exclude the possibility that other settings could have been suitable for the intervention also.

\section{Effect evaluation}

The randomization process yielded an unequal distribution of numbers of students in lower and higher education, ethnicity, self-efficacy and boy/girl-friend smoking between the control and intervention schools. However, when controlling for these potential confounders we found no effect of the odds ratio estimates on any of the intervention effects.

Multilevel analysis with the factor 'intervention' included in the model did not converge due to small numbers. Therefore, it was not possible to adjust. for possible school effects in the analysis. However, multilevel analysis of single variables indicated no effect of school level on data. In addition, the matched design took into account possible effects of geographical and school type dif- 
ferences. Third, since only two school types were entolled little vatiation could be expected between schools. We therefore assess that there was only a limited chance that school influences have biased our results.

We had no biochemical validation of self-reports on smoking. Although self-reports have been found reliable in many adolescent smoking studies (102) there is still debate on this issue, especially in cases where self-reports are used in controlled trials (103). Potentially unreliability in self-reports, however, would only be a major problem if there were differences in reliability of self-reported between the intervention and the control gtoup. To increase the reliability of the self-reports in our study, we tried to secure tesponse confidentiality by means of careful confidentiality procedures, for example with using a non petsonal identification code.

\section{Interpretation of results}

It is obvious that interventions based on potentially effective methods and strategies are ineffective if they are not used. Since our pilot study indicated that the recruitment of smokers is a major barrier in adolescent smoking cessation, this has been a main focus in the study. Rogers (1995) suggests that the perception of relative advantage, complexity, compatibility in the target group is crucial when understanding the willingness of individuals to engage in new innovations/behaviors (104). In addition, he emphasizes that innovations that ate observable and trialable are easier adopted than innovations which is not.

Both our pilot study and the qualitative study of the youth smoking cessation process indicated, that in spite of the fact that many adolescents were motivated to quit smoking, they did not experience benefits of participating in a smoking cessation intervention, and participation was not compatible with the beliefs of the target group: They did not experience that cessation was related to skills that could be learned. Instead, they considered successful smoking cessation as a matter of will-power and expected interventions to be patronizing, and something one would only do if one had a serious problem, such as drug- or alcohol dependency.

This suggested that any smoking cessation aid would suffer from major: recruitment problems, unless the implementation would include some kind of mandatory or authoritative entollment procedure.

In our intervention participation was completely volunary and there was no pressure from the schools towards participation. Further, the cessation events were held at relatively large schools and no special marketing effort was made to make students participate. The students participated in our intervention program because they either passed by the cessation stand by chance when visiting the school cantina, or because they were encouraged by friends or classmates. Since the schools did not allow students to use school hours for participation, participants had to use their breaks or free periods when participating. Still a sizeable 
amount of the daily smokers participated in the intervention, indicating that the negative perceptions towards smoking cessation interventions can be overruled if the conditions are tight.

We do not have data that can justify a firm conclusion on which factors were important for the tecruitment of smokers. However, the fact that we based the intervention on specific factors that were found to be important for recruitment, the observations at the intervention sites and feedback from both counselors and students gave some clear indications. Our interpretation is that it was the easy access combined with a non-patronizing approach, a motivational incentive (the $\mathrm{CO}$ measurements) and the high flexibility and tailoring in the interventions are crucial for recruitment. The easy access not only reduced complexity of participation, but also made the intervention highly observable, and in that way put the intervention on the 'agenda' among the students at the schools. Thus we tecommend that future intervention should include these elements in their design.

\section{Lack of long term effects}

Out intervention did not manage to maintain the short-term effects at one-year follow-up. This lack of long-term intervention success can be caused by many factors. Interventions can address the wrong determinants, set up the wrong change objectives, or use inappropriate methods or strategies. In addition seemingly well-developed programs can be poorly implemented either because they are not used, or because they are executed impropetly.

Since there is a strong agreement for the theoretical basis of our intervention and the recommendations from major teview in the area $(71 ; 77 ; 89)$, it is unlikely that we selected the wrong theoretical methods for our intervention. This idea is further supported by the fact that we did find short-term behavioural change accomplished by changes in both self-efficacy and cessation intentions. However, Intervention Mapping emphasises that theoretical change methods and strategies are only effective within certain parameters or conditions. Seemingly appropriate methods might be ineffective if conditions are inadequately taken into consideration. One possible interpretation of our results is that the format with short counselling and self-help materials did not provide the necessary conditions for achieving long-term effects simply because it was not comprehensive enough. In short, one could say that we choose the right methods but the wrong strategy (short counselling).

Another interpretation is that the lack of long-term success was caused by low quality of intervention delivery of the program. Counsellors had a central role with this regatd, and although all counsellors received special training for the program and had a background relevant for the project, the quality of implementation might have differed between intervention schools. Unfortunately we do not have direct measures of implementation quality. The only quantita- 
tive indicator for implementation quality is the number of recruited students at the school level. We found a relatively wide variation in numbers of recruited students between schools indicating of some kind of differences at this level. However, we cannot rule out that this difference could be caused be factors unrelated to counsellors (like school building structure or the like). In addition, we interviewed one representative from each school with regard to their experience with holding the events at the schools. Although the interviews tevealed that the counsellors had positive experiences with the events and that they reported they felt qualified for the project, these interviews were not appropriate to justify a quality assessment of the counselling at the events.

\section{Future interventions}

In a wider perspective the tesults of this intervention have some implications for future research and intervention development. Our trial shows that it possible in best cases - to get in contact with more than $75 \%$ of all adolescent smokers at an educational institution and that short-term effects can be achieved. However, the study also showed that the approach was unable to produce long-term results, and therefore it is questionable whether the intervention can be recommended in its current format. McGuire emphasizes that the communication channels that are effective increasing attention about a message not necessarily are suitable for obtaining long-term change (105). One way of improving the intervention would be to incorporate booster sessions or to enhance the impact of the intervention by securing more counseling time for the participants. The latter would involve some kind of agreement with the schools giving students the 'right' to use teaching time to participate in the intervention. Second, the intervention can be combined with other more intensive interventions like group counseling, individual counseling, telephone counseling or intensive internet support. In the ideal example a variety of opportunities were available for all smokers making it possible for the adolescents to test and experiment various support methods dependent on their motivation and personal preferences. 


\section{Events for Adolescent Smoking Cessation}

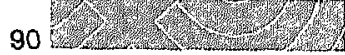


6 Summary

㖥 
Events for Adolescent Smoking Cessation 
In this thesis we have described the development and evaluation of an evidence based adolescent smoking cessation progtam. Our introductory work identified a major paradox with regard to adolescent smoking cessation: Although more than $40 \%$ of all smokers reported that they have tried to quit smoking within the last 12 months, the majority of adolescents indicates that they would not participate in a smoking cessation intervention. In addition our pilot study showed that it would be difficult to implement smoking cessation interventions in the Danish school setting. Therefore the main questions for this thesis have been: 1) Which are the effective methods and strategies for adolescent smoking cessation? 2) How do we communicate or deliver these in a format that is easily implemented in a Danish school setting and in a way that we recruit a sizeable amount of adolescent smokers?

As part as the needs assessment research we conducted a qualitative study with group discussions and individual interviews during April-May 2004 with 26 persons aged 15-21yts who all initiated a quit attempt on 1 January 2004. The main research questions were 1) Which cognitive and behavioural strategies do adolescents use in their attempts to quit smoking? 2) Which attitudes and beliefs do adolescents have towards the process of smoking cessation and smoking cessation interventions? The main finding was that adolescent smoking cessation should be seen as an individual process and that all stages in this process are characterized by a broad variety of quit and maintenance strategies. We could not identify a strategy being superior in explaining the success of quit attempts, but we found that success was related to whether or not the quitter was committed to a learning process in which different strategies were tested, evaluated re-tested, et cetera. In addition the study revealed that adolescents considered 'willpower' as the most important deteminant of smoking cessation, that they expected cessation interventions to be patronizing, and that they regarded seeking support for an internal personal process as excessive.

We used the Intervention Mapping (IM) as framework for planning the smoking cessation intervention. Based on a needs assessment we identified important and changeable determinants of cessation behaviour, specified change objectives for the intervention program, selected theoretical change methods for accomplishing intervention objectives, and finally operationalized change methods into practical intervention strategies. We found that adolescent smoking cessation should be seen as a process influenced by both individual determinants (e.g. knowledge, attitudes, self-efficacy and coping skills) and interpersonal determinants (e.g. friends support), and that quiting was related to the following performance objec- 
tives: Decide to quit, decide to make a committed effort to quit, prepare coping plans, quit smoking, identify trigger situations, make/perform coping plans, and evaluate and adjust coping strategies. Further we identified a line of change objectives related to each of these performance objective and we identified SelfRegulation Theory, the Trans Theoretical Model and Social Cognitive Theory (85) as relevant theories for program development, and from these theories we selected guided practice, modelling, self-monitoring, coping planning, consciousness ratsing, dramatic relief and decisional balance as methods suitable for adolescent smoking cessation interventions. In the strategic translation of these methods into practical strategies, we selected 'biofeedback', 'Motivational Interviewing' and 'Behavioural Journalism' as the main intervention strategies. Since the anticipation of implementation and rectuitment of smokers was crucial in the intervention development, we secured in the production phase that the intervention format took into account the factors found in the needs assessment that seemed essential for tecruitment and implementation. Consequently, we designed an intervention based upon voluntary participation that did not require registration beforchand, that was easy accessible, that included the provision of motivational incentives and a non-patronizing support.

We tested the intervention in a cluster randomised trial at 22 continuation schools for students age 15-21. Our main research questions were whether the intervention was effective in reaching a sizeable amount of the adolescent daily smokers, and whether it was effective in increasing the one-month- and 14 month cessation rates. In addition, we tested whether the intervention had any effects on short and long term cessation attempt and factors thought to influence the cessation process. We found positive short term effects of the intervention regarding cessation, self-efficacy change and intention change. However, none of these effects were maintained at one-year follow up. The intervention was successful in reaching more than half of all daily smokers in the target group with more than $30 \%$ receiving counseling at least once in the intervention period. Process evaluations showed a high level of satisfaction with the intervention among the counselors and schools ptincipals, but also tevealed a large variation in reach between schools indicating room for improvement in future interventions.

In a wider perspective our project have shown that it is possible to develop an intervention that is easily implemented in a Danish school educational setting and that we can achive modest short term effects, but that additional research is needed in order to maintain the effects at long term.

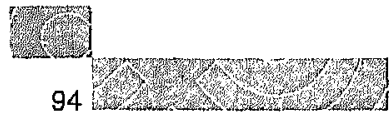




\section{Reference List}


Events for Adolescent Smoking Cessation

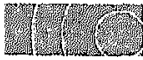

96 


\section{Reference List}

(1) Juel K, Sørensen J, Brønnum-Hansen H. Risikofaktorer og folkesundhed i Danmark. Statens Institut for Folkesundhed; 2006.

(2) The Health Consequenses of Smoking. A Report of the Surgeon General. Department of Health and Human services. 2004.

(3) National Kraftplan. Sundhedsministeriet; 2000.

(4) Bernaards CM, Twisk JW, Van MW, Snel J, Kemper HC. A longitudinal study on smoking in relationship to fitness and heart rate response. Med Sci Sports Exerc 2003 May;35(5):793-800.

(5) Silverstein P. Smoking and wound healing. Am J Med 1992 Jul 15;93(1A):22S-4S.

(6) Grady D, Ernster V. Does cigatette smoking make you ugly and oid? Am J Epidemiol 1992 Apr 15;135(8):839-42.

(7) Naldi L. Cigarette smoking and psoriasis. Clin Dermatol 1998 Sep;16(5):571-4.

(8) Frye RE, Schwartz BS, Doty RL. Dose-related effects of cigarette smoking on olfactory function. JAMA 1990 Mar 2;263(9):1233-6.

(9) DeBlack SS. Cigarette smoking as a risk factor for cataract and agerelated macular degeneration: a review of the literature. Optometry 2003 Feb;74(2):99-110.

(10) Tonetti MS. Cigarette smoking and periodontal diseases: etiology and management of disease. Ann Periodontol 1998 Jul;3(1):88-101.

(11) Augood C, Duckitt K, Templeton AA. Smoking and female infertility: a systematic review and meta-analysis. Hum Reprod 1998 Jun;13(6):1532-9.

(12) Holmen TL, Barrett-Connor E, Holmen J, Bjermer L. Health problems in teenage daily smokers versus nonsmokers, Norway, 1995-1997: the NordTrondelag Fealth Study. Am J Epidemiol 2000 Jan 15;151(2):148-55.

(13) Rius C, Fernandez E, Schiaffino A, Borras JM, Rodriguez-Artalejo F. Self perceived health and smoking in adolescents. J Epidemiol Community Health 2004 Aug;58(8):698-9.

(14) Wiencke JK, Thurston SW, Kelsey K'T, Varkonyi A, Wain JC, Mark EJ, et al. Early age at smoking initiation and tobacco carcinogen DNA damage in the lung. J Natl Cancer: Inst 1999 Apr 7;91(7):614-9.

(15) Wiencke JK, Kelsey KT. Teen smoking, field cancerization, and a "critical period" hypothesis for lung cancer susceptibility. Environ Health Perspect 2002 Jun;1 10(6):555-8. 
(16) Dalum P, Jensen PD, Nielsen GA. Rygestop og unge - Et litteratur og interventionsstudie [Adolescent smoking cessation- A litterature and intervention study]. Danish Cancer Society; 2004.

(17) McDonald PW. Population-based recruitment for quit-smoking programs: an analytic review of communication variables. Prev Med JID - 0322116 1999 Jun;28(6):545-57.

(18) Backinger CL, McDonald P, Ossip-Klein DJ, Colby SM, Maule CO, Fngan $\mathrm{P}$, et al. Improving the future of youth smoking cessation. Am J Health Behav 2003;27 Suppl 2:S170-S184.

(19) Balch GI. Exploting perceptions of smoking cessation among high school smokers: input and feedback from focus groups. Prev Med JID - 0322116 1998 Sep;27(5 Pt 3):A55-A63.

(20) Balch GI, Tworek C, Barker DC, Sasso B, Mermelstein R, Giovino GA. Opportunities for youth smoking cessation: findings from a national focus group study. Nicotine Tob Res 2004 Feb;6(1):2-17.

(21) Stanton WR, Lowe JB, Fisher KJ, Gillespie AM, Rose JM. Beliefs about smoking cessation among out-of-school youth. Drug Alcohol Depend JID - 75135871999 May 3;54(3):251-8.

(22) Lawrance KG. Adolescent smokers' preferted smoking cessation methods. Can J Public Health JID - 03727142001 Nov;92(6):423-6.

(23) Groth M, Nielsen GA, Ringgård L. Unges Livsstil og Dagligdag 2001. Geografiske forskelle og ligheder. Kræftens Bekæmpelse og Sundhedsstyrelsen; 2003.

(24) Paavola M, Vartiainen E, Puska P. Predicting adult smoking: the influence of smoking during adolescensce and smoking among friends and family. Health Education Research 1996:11(3):309-15.

(25) Paavola M, Vartiainen E, Puska P. Smoking cessation between teenage years and adulthood. Health Educ Res JID - 86084592001 Feb;16(1):49-57.

(26) Stanton WR, Lowe JB, Gillespie AM. Adolescents' experiences of smoking cessation. Drug Alcohol Depend JID - 75135871996 Dec 2;43(1-2):63-70.

(27) Sussman S, Dent CW, Severson H, Burton D, Flay BR. Self-initiated quitting among adolescent smokers. Prev Med JID - 03221161998 Sep;27(5 Pt 3):A19-A28.

(28) Liang L, Chaloupka FJ. Differential effects of cigarette price on youth smoking intensity. Nicotine Tob Res JID - 98157512002 Feb;4(1):109-14.

(29) Biener L, Aseltine RHIJ, Cohen B, Anderka M. Reactions of adult and teenaged smokers to the Massachusetts tobacco tax. Am J Public Health JID - 12540741998 Sep;88(9):1389-91.

(30) Forster JL, Murray DM, Wolfson M, Blaine TM, Wagenaar AC, Hennrikus DJ. The effects of community policies to reduce youth access to tobacco. Am J Public Health JID - 12540741998 Ang;88(8):1193-8.

(31) Ary DV, Biglan A. Longitudinal changes in adolescent cigarette smoking behavior: onset and cessation. J Behav Med JID - 78071051988 Aug;11(4):361-82. 
(32) Burt RD, Peterson AVJ. Smoking cessation among high school seniors. Prev Med JID - 0322116 1998 May;27(3):319-27.

(33) Chassin L, Presson CC, Sherman SJ. Cognitive and social influence factors in adolescent smoking cessation. Addict Behav JID - 7603486 1984;9(4):383-90.

(34) Chen PH, White HR, Pandina RJ. Predictors of smoking cessation from adolescence into young adulthood. Addict Behav JID - 76034862001 Jul;26(4):517-29.

(35) Ellickson PL, McGuigan KA, Klein DJ. Predictors of late-onset smoking and cessation over 10 years. J Adolesc Health JID - 91021362001 Aug;29(2):101-8.

(36) Ellickson PL, Tucker JS, Klein DJ. Sex differences in predictors of adolescent smoking cessation. Health Psychol JID - 82115232001 May;20(3):186-95.

(37) Hansen WB, Collins LM, Johnson CA, Graham JW. Self-initiated smoking cessation among high school students. Addict Behav JID - 7603486 1985;10(3):265-71.

(38) Lewinsohn PM, Brown RA, Seeley JR, Ramsey SE. Psychosocial correlates of cigarette smoking abstinence, experimentation, persistence and frequency during adolescence. Nicotine Tob Res JID - 98157512000 May;2(2):121-31.

(39) Tucker JS, Ellickson PL, Klein DJ. Smoking cessation during the transition from adolescence to young adulthood. Nicotine Tob Res $20(12$ Aug;4(3):321-32.

(40) Skinner WF, Massey JL, Ktohn MD, Lauer RM. Social influences and constraints on the initiation and cessation of adolescent tobacco use. J Behav Med JID - 78071051985 Dec;8(4):353-76.

(41) Pallonen UE, Prochaska JO, Velicer WF, Prokhotov AV, Smith NI: Stagres of acquisition and cessation for adolescent smoking: an empirical integration. Addict Behav JID - 76034861998 May;23(3):303-24.

(42) Chassin L, Presson CC, Rose JS, Sherman SJ. The natural history of cigalrette smoking from adolescence to adulthood: demographic predicters of continuity and change. Health Psychol JID - 82115231996 Nov;15(6):478, 84.

(43) Zhu SH, Sun J, Billings SC, Choi WS, Malarcher A. Predictors of smoking cessation in U.S. adolescents. Am J Prev Med JID - $87(14773$ 1999) Apr; 16(3):202-7.

(44) Chassin L, Presson C, Rose J, Sherman SJ, Prost J. Parental smoking cessation and adolescent smoking. J Pediatt Psychol JID - 780177320002 Sep;27(6):485-96.

(45) Farkas AJ, Distefan JM, Choi WS, Gilpin EA, Pierce JP. Does parental smoking cessation discourage adolescent smoking? Prev Med JID 03221161999 Mar;28(3):213-8. 
(46) O'Byrne KK, Haddock CK, Poston WS. Parenting style and adolescent smoking. J Adolesc Health JID - 91021362002 Jun;30(6):418-25.

(47) Siqueira LM, Rolnitzky LM, Rickert VI. Smoking cessation in adolescents: the role of nicotine dependence, stress, and coping methods. Arch Pediatr Adolesc Med JID - 94227512001 Apr;155(4):489-95.

(48) Prokhorov AV, Pallonen UE, Fava JL, Ding L, Niaura R. Measuring nicotine dependence among high-risk adolescent smokers. Addict Behav JID - 76034861996 Jan;21(1):117-27.

(49) Sargent JD, Mott LA, Stevens M. Predictors of smoking cessation in adolescents. Arch Pediatr Adolesc Med JID - 94227511998 Apr;152(4):388-93.

(50) Schmid $\mathrm{H}$. Predictors of cigarette smoking by young adults and readiness to change. Subst Use Misuse JID - 96021532001 Sep;36(11):1519-42.

(51) Engels RC, Knibbe RA, de Vties H, Drop MJ. Antecedents of smoking cessation among adolescents: who is motivated to change? Prev Med JID 03221161998 May;27(3):348-57.

(52) Bonard L, Janin-Jacquat B, Michaud PA. Who are the adolescents who stop smoking? Eur J Pediatr JID - 76038732001 Jul;160(7):430-5.

(53) Rose JS, Chassin L, Presson CC, Sherman SJ. Prospective predictors of quit attempts and smoking cessation in young adults. Health Psychol JID $82115231996 \mathrm{Jul} ; 15(4): 261-8$.

(54) Hu TW, Lin Z, Keeler TE. Teenage smoking, attempts to quit, and school performance. Am J Public Health JID - 12540741998 Jun;88(6):940-3.

(55) Romer D, Jamieson P. Do adolescents appreciate the risks of smoking? Evidence from a national survey. J Adolesc Health JID - 91021362001 Jul;29(1):12-21.

(56) Milam JE, Sussman S, Ritt-Olson A, Dent CW. Perceived invulnerability and cigarette smoking among adolescents. Addict Behav JID - 7603486 2000 Jan;25(1):71-80.

(57) Prokhorov AV, Hudmon KS, de Moor CA, Kelder SH, Conroy JL, Ordway N. Nicotine dependence, withdrawal symptoms, and adolescents' teadiness to quit smoking. Nicotine Tob Res JID - 98157512001 May;3(2):151-5.

(58) Adelman WP, Duggan AK, Hauptman P, Joffe A. Effectiveness of a high school smoking cessation program. Pediatrics JID - 03764222001 Apr;107(4):E50.

(59) Coleman-Wallace D, Lee JW, Montgomery S, Blix G, Wang DT. Evaluation of developmentally appropriate programs for adolescent tobacco cessation. J Sch Health JID - 03763701999 Oct;69(8):314-9.

(60) Dino G, Horn K, Goldcamp J, Fernandes A, Kalsekar I, Massey C. A 2-year efficacy study of not on tobacco in Florida: an overview of program successes in changing teen smoking behavior. Prev Med JID $03221162001 \mathrm{Dec} ; 33(6): 600-5$.

(61) Prince F. The relative effectiveness of a peer-led and adult-led smoking intervention program. Adolescence JID - 0123667 1995;30(117):187-94. 
(62) Sussman S, Dent CW, Lichtman KL. Project EX: outcomes of a teen smoking cessation program. Addict Behav JID - 76034862001 May;26(3):42538.

(63) Hurt RD, Croghan GA, Beede SD, Wolter TD, Croghan IT, Patten CA. Nicotine patch therapy in 101 adolescent smokers: efficacy, withdrawal symptom relief, and carbon monoxide and plasma cotinine levels. Arch Pediatr Adolesc Med JID - 94227512000 Jan;154(1):31-7.

(64) Patten CA, Ames SC, Ebbert JO, Wolter TD, Hurt RD, Gauvin TR. Tobacco use outcomes of adolescents treated clinically for nicotine dependence. Arch Pediatr Adolesc Med JID - 94227512001 Jul;155(7):831-7.

(65) Hafstad A, Aaro LE, Engeland A, Andersen A, Langmark F, Stray-Pedersen $B$. Provocative appeals in anti-smoking mass media campaigns targeting adolescents--the accumulated effect of multiple exposures. Health Educ Res JID - 86084591997 Jun;12(2):227-36.

(66) Woodruff SI, Fdwards CC, Conway TL, Elliott SP. Pilot test of an Internet virtual world chat room for rural teen smokers. J Adolesc Health JID -9102136 2001 Oct:29(4):239-43.

(67) O'Neill HK, Gillispie MA, Slobin K. Stages of change and smoking cessation: a computer-administered intervention program for young adults. Am J Health Promot JID - 87016802000 Nov;15(2):93-6, iii.

(68) Colby SM, Monti PM, Barnett NP, Rohsenow DJ, Weissman K, Spirito A, et al. Brief motivational interviewing in a hospital setting for adolescent smoking: a preliminary study. J Consult Clin Psychol JID - 01365531998 Jun;66(3):574-8.

(69) Kentala J, Utriainen P, Pahkala K, Mattila K. Can brief intervention through community dental care have an effect on adolescent smoking? Prev Med JID - ()322116 1999) Aur;29(2):1(17-11.

(70) Quinlan KB, McCaul KD. Matched and mismatched interventions with young adult smokers: testing a stage theory. Fealth Psychol JID - 8211523 2000 Mar;19(2):165-71.

(71) McDonald P, Colwell B, Backinger Cl., Husten C, Maule CO. Better: practices for youth tobacco cessation: evidence of tevicw panel. Am J Health Behav 2003;27 Suppl 2:S144-S158.

(72) Milton MH, Maule CO, Backinger Cl, Gregory DM. Recommendations and guidance for practice in youth tobacco cessation. $\mathrm{Am} J$ Health Behav 2003;27 Suppl 2:S159-\$169.

(73) Bartholomew LK, Parcel GS, Kok G, Gottlieb NHI, Planning Health Promotion Ptograms - $\Lambda \mathrm{n}$ Intervention Mapping $\Lambda$ pptoach. Second edition ed. Jossey-Bass; 2006.

(74) Abraham C, Michie S. $\Lambda$ taxonomy of behavior change techniques used in interventions. Health Psychol 2008 May;27(3):379-87.

(75) Glasziou P, Meats E, Heneghan C, Shepperd S. What is missing from descriptions of theatment in trials and reviews? BMJ $20(18$ Jun $28 ; 336(7659): 1472-4$. 
(76) Pallonen UE, Murray DM, Schmid L, Pirie P, Luepker RV. Patterns of self-initiated smoking cessation among young adults. Health Psychol JID $82115231990 ; 9(4): 418-26$.

(77) Grimshaw GM, Stanton A. Tobacco cessation interventions for young people. Cochrane Database Syst Rev 2006;(4):CD003289.

(78) Leatherdale ST. School-based smoking cessation programs: do youth smokers want to participate in these programs? Addict Behav 2006 Aug;31(8):1449-53.

(79) Hammond D, McDonald PW, Fong GT, Borland R. Do smokers know how to quit? Knowledge and perceived effectiveness of cessation assistance as predictors of cessation behaviour. Addiction 2004 Aug;99(8):1042-8.

(80) Al-Delaimy WK, White MM, Pierce JP. Adolescents' perceptions about quitting and nicotine replacement therapy: findings from the California Tobacco Survey. J Adolesc Health 2006 Apr;38(4):465-8.

(81) Amos A, Wiltshire S, Haw S, McNeill A. Ambivalence and uncertainty: experiences of and attitudes towards addiction and smoking cessation in the mid-to-late teens. Health Educ Res 2006 Apr;21(2):181-91.

(82) Leatherdale ST, McDonald PW. What smoking cessation approaches will young smokers use? Addict Behav 2005 Sep;30(8):1614-8.

(83) Prochaska JO, DiClemente CC, Norctoss JC. In search of how people change. Applications to addictive behaviors. Am Psychol 1992 Sep;47(9):1102-14.

(84) Pallonen UE. Transtheoretical measures for adolescent and adult smokers: similarities and differences. Prev Med JID - 03221161998 Sep;27(5 Pt 3):A29-A38.

(85) Bandura A. Social foundations of thought and action: A social cognitive theory. Englewood Cliffs: Prentice Hall; 1986.

(86) Kvale S. InterViews -an Introduction to Qualitative Research Interviewing. SAGE publications; 1996 . p. 187-209.

(87) Latabie LC. To what extent do smokers plan quit attempts? Tob Control 2005 Dec;14(6):425-8.

(88) West R, Sohal T. "Catastrophic" pathways to smoking cessation: findings from national survey. Brit Med J 2006 Feb 25;332(7539):458-60.

(89) Sussman S, Sun P, Dent CW. A meta-analysis of teen cigarette smoking cessation. Health Psychol 2006 Sep;25(5):549-57.

(90) Leatherdale ST, McDonald PW. Youth smokers' beliefs about different cessation approaches: are we providing cessation interventions they never intend to use? Cancer Causes Control 2007 Sep;18(7):783-91.

(91) West R, McNeill A, Raw M. Smoking cessation guidelines for health professionals: an update. Health Education Authority. Thorax 2000 Dec;55(12):987-99.

(92) Valery L, Anke O, Inge KK, Johannes B. Effectiveness of smoking cessation interventions among adults: a systematic review of reviews. Eur ] Cancer Prev 2008 Nov;17(6):535-44. 
(93) USDHHS. Psychosocial tisc factors for initiating trobacco use. From: Preventing tobacco use among young people: a report of the surgeon general. US Department of Health and Human Service, Centers for Disease Control and Prevention, National Center for Cronic Disease Prevention and Health Promotion, Office on Smoking and Health.; 1994.

(94) Dalum P, Schaalma H, Nielsen GA, Kolk G. "I did it my way"-- $\Lambda$ n explorative study of the smoking cessation process among Danish youth. Patient Educ Couns (2008), doi:10 1016/j pec 200806 012. In press 2008.

(95) Clark NM, Zimmerman BJ. A social cognitive view of self-regulated learning about health. Health Educ Res 199();5(3):371-9.

(96) Health Behavior and Health Education - Theory, Research, and Practice. Second Edition ed. 1997.

(97) Lipkus IM, Prokhorov AV. The effects of providing lung age and respiratory symptoms feedback on community college smokers' perceived smoking-related health risks, worries and desire to quit. Addict Behav 20017 Mar;32(3):516-32.

(98) Miller WR, Rollnick S. Motivational Interviewing. 2008.

(99) Kok G, Schaalma H, Ruiter RA, van FiP, Brug J. Intervention mapping: protocol for applying health psychology theory to prevention programmes. J Health Psychol 20114 Jan;9(1):85-98.

(100) Dalum P, Schaalma H, Niclsen GA, Kok G. "I did it my way"-An explo.. rative study of the smoking cessation process among Danish youth. Paltient Educ Couns 2008 Jul 25.

(101) Dino GA, Horn KA, Goldcamp J, Maniar SD, Fernandes $\Lambda$, Malsscy (:) Statewide demonstration of not on tobacco: a gender-sensitive reen stmoking cessation program. J Sch Nurs JID - 920)6498 20101 Apr;: 17(2):9(1).7.

(102) Hansen WB, Malotte CK, lielding JF. The bogus pipeline revisited; the use of the threat of detection as a means of increasing sclf-reports of tobacco use. J Appl Psychol 1985 Nov;7()(4):789-92.

(103) Mermelstein R, Colby SM, Patten C, Prokhoroy A, Brown R, Myers M, et al. Methodological issues in measuring treatment outcome in adolescent smoking cessation studies. Nicotine Tob Res 20102 Nov;4(4):39):5411.3.

(104) Rogers EM. Diffusion of Innovasions. L'ourth Eclition ed. The lirec Press; 1995.

(105) McGuire WJ. Atcitudes and atcitude change. In: I inderey (i, Aronson Li, editors. The handbook of social psychology: vol, 2. Special fields and ap?plications. Third ed. 20(18. p. 23.3-346. 